Running Title: DIETARY RESCUE OF FMR1 KNOCKOUT

\title{
DIETARY RESCUE OF ADULT BEHAVIORAL DEFICITS IN THE FMR1 KNOCKOUT MOUSE
}

Suzanne O. Nolan ${ }^{1}$, Samantha L. Hodges ${ }^{2}$, Matthew S. Binder ${ }^{1}$, Gregory D. Smith ${ }^{2}$, James T. Okoh $^{1}$, Taylor S. Jefferson ${ }^{1}$, Brianna Escobar ${ }^{1}$, Joaquin N. Lugo $^{1,2^{*}}$

${ }^{1}$ Department of Psychology and Neuroscience, ${ }^{2}$ Institute of Biomedical Studies, Baylor University, Waco, TX 76798, USA

Corresponding Author Information:

Joaquin N. Lugo, PhD

Baylor University

Department of Psychology and Neuroscience

One Bear Place \# 97334

Waco, TX 76798

Phone: 254-710-2389; FAX: 254-710-3033

E-mail: joaquin_lugo@baylor.edu 


\section{DIETARY RESCUE OF FMR1 KNOCKOUT}

\section{ABSTRACT}

The current study aimed to further address important questions regarding the therapeutic efficacy of omega-3 fatty acids for various behavioral and neuroimmune aspects of the Fmr1 phenotype. To address these questions, our experimental design utilized two different omega-3 fatty acid administration timepoints, compared to both standard laboratory chow controls ("Standard") and a diet controlling for the increase in fat content ("Control Fat"). In the first paradigm, post-weaning supplementation (after postnatal day 21) with the omega-3 fatty acid diet ("Omega-3") reversed deficits in startle threshold, but not deficits in prepulse inhibition, and the effect on startle threshold was not specific to the Omega-3 diet. However, post-weaning supplementation with both experimental diets also impaired acquisition of a fear response, recall of the fear memory and contextual fear conditioning compared to the Standard diet. The postweaning Omega-3 diet reduced hippocampal expression of IL-6 and this reduction of IL-6 was significantly associated with diminished performance in the fear conditioning task. In the prenatal experimental paradigm, the Omega-3 diet attenuated hyperactivity and acquisition of a fear response. Additionally, prenatal exposure to the Control Fat diet (similar to a "Western" diet) further diminished nonsocial anxiety in the Fmr1 knockout. This study provides significant evidence that dietary fatty acids throughout the lifespan can significantly impact the behavioral and neuroimmune phenotype of the Fmr1 knockout model. 


\section{DIETARY RESCUE OF FMR1 KNOCKOUT}

\section{INTRODUCTION}

Fragile $\mathrm{X}$ syndrome $(\mathrm{FXS})$ is a neurodevelopmental disorder resulting from a trinucleotide (CGG) repeat mutation in the fragile $\mathrm{X}$ mental retardation (FMR1) gene, which codes for the Fragile $\mathrm{X}$ mental retardation protein (FMRP). Mutations in FMR1 are one of the most prevalent genetic contributors to inherited intellectual disability (Turner, Webb, Wake, \& Robinson, 1996) and Autism spectrum disorder (ASD) (Kaufmann et al., 2004). In clinical studies, individuals with FXS display a myriad of behavioral abnormalities, including significant cognitive dysfunction, autistic behaviors, and hyperactivity (Hagerman \& Sobesky, 1989). These phenotypes are often mirrored in the Fmr1 knockout mouse, which demonstrates significant learning impairments, hyperactivity, social impairments, and increased repetitive behavior, among other behavioral phenotypes (Liu \& Smith, 2009; Nolan et al., 2017; Veeraragavan et al., 2011). Alongside these behavioral phenotypes, recent clinical investigations have also demonstrated significant evidence for the role of cytokine signaling in the present population (Ashwood et al., 2011; Ashwood, Nguyen, Hessl, Hagerman, \& Tassone, 2010). Previous clinical and pre-clinical studies have shown evidence of aberrant proinflammatory signaling as a key feature in both FXS and its comorbid condition, ASD populations and models (Ashwood et al., 2011; Ashwood et al., 2010; Hodges, Nolan, Taube, \& Lugo, 2017; Pietropaolo et al., 2014).

Omega-3 fatty acids, a potent anti-inflammatory has been investigated for the potential to alleviate behavioral symptoms in clinical populations of both ASD (Amminger et al., 2007) and Rett syndrome (De Felice et al., 2012). Treatment with omega-3 fatty acids incorporates several potential mechanisms that may be relevant to the Fmr1 knockout. First, eicosapentaenoic acid (EPA) and docosahexaenoic acid (DHA), two of the primary omega-3 fatty acids, are significant components of the neuronal membrane, and their composition in this membrane regulates functioning of key transmembrane receptors and other proteins (Frisardi, Panza, Seripa, Farooqui, \& Farooqui, 2011). Previous work has demonstrated that even one membrane substitution of a single-bonded polyunsaturated fatty acid (PUFA) for a double- 


\section{DIETARY RESCUE OF FMR1 KNOCKOUT}

bonded PUFA exerts changes in membrane properties that in turn alter constitutive activity of integral membrane proteins, such as rhodopsin (Eldho, Feller, Tristram-Nagle, Polozov, \& Gawrisch, 2003). Mechanistically, increasing the bioavailability of long chain polyunsaturated fatty acids may also enable important anti-inflammatory mechanisms (Kang \& Weylandt, 2008). These may be accomplished through a variety of methods, including interactions with G-protein coupled receptors or downstream production of small anti-inflammatory compounds (Oh et al., 2010). There is also significant evidence for an influence of DHA on markers of synaptogenesis and expression of glutamate receptors (Cao et al., 2009). Further, limited preclinical evidence finds that post-weaning treatment with omega- 3 fatty acids resulted in improvements in novelty exploration, social interaction, and object recognition in association with reductions in neuroinflammatory signaling markers in the adult $F m r 1$ mouse model (Pietropaolo et al., 2014).

While the aforementioned evidence supports a role of omega-3s as a potential therapeutic for the Fmr1 knockout phenotype, it is unknown if administration of this intervention at an earlier timepoint would result in differential effects on the behavioral and neuroinflammatory phenotypes studied. Accumulation of fatty acids is fundamental for the formation of neuronal membranes, particularly early in development (Yehuda, 2012). Studies of fatty acid incorporation demonstrate that essential long chain polyunsaturated fatty acids, such as DHA and EPA, are not absorbed and incorporated appropriately during development in children with ASD (Vancassel et al., 2001). Moreover, increased bioavailability of fatty acids during early development can induce discernable phenotypic changes as early as the weaning point (Bongiovanni, Depeters, \& Van Eenennaam, 2007). While no studies have examined the therapeutic potential of prenatal administration in the Fmr1 model, previous studies have supported the potential for prenatal omega-3 fatty acids in the reversal of autistic-like deficits in other ASD rodent models (Fortunato et al., 2017; Garay, Hsiao, Patterson, \& McAllister, 2013; Li et al., 2015; Malkova, Yu, Hsiao, Moore, \& Patterson, 2012). 


\section{DIETARY RESCUE OF FMR1 KNOCKOUT}

The current study aimed to address questions regarding the therapeutic efficacy of omega-3 fatty acids for key aspects of the Fmr1 phenotype, such as whether the behavioral effects might be mediated through changes in inflammatory gene expression, whether timing matters, and how previous effects compare when referenced to a standard dietary control. The behavioral measures were selected first as they most appropriately reflect the FXS clinical phenotype (Hagerman \& Hagerman, 2002), and due to prior findings (Nolan et al., 2017). In the first experiment, we exposed male Fmr1 knockouts to dietary manipulations in the post-weaning period and examined various aspects of adult behavior and cytokine signaling markers. In the second experiment, we administered similar dietary manipulations during the prenatal period to investigate how prenatal dietary manipulations prior to weaning will influence these same behaviors and cytokine signaling markers during adulthood in male $F m r 1 \mathrm{KO}$ mice.

\section{MATERIALS AND METHODS}

\section{Animals}

All procedures were performed in accordance with Baylor University Institutional Care and Use Committee and the Guide for the Care and Use of Laboratory Animals of the National Institutes of Health. Male Fmr1 ${ }^{+/+}$and female Fmr1 ${ }^{+/-}$FVB.129P2-Pde6b+Tyrc-ch Fmr1tm1Cgr/J (Jackson Labs Stock No: 004624) mice originally from Jackson Labs were housed at Baylor University and bred to produce male wildtype (WT) and Fmr1 knockout (KO) offspring. The colony was maintained on a 12-hour light/dark cycle (lights on at 7 am). On postnatal day (PD) 7, pups were separated from parents and a toe-clipping identification system was used to identify animals and the tissue was sent out for genotyping and preserved in $70 \%$ ethanol (Mouse Genotype, Escondido, CA, USA). Animals were housed in the Special Research Unit at the Baylor Science Building. All tested animals and their breeders had access to food and water ad libitum. 
bioRxiv preprint doi: https://doi.org/10.1101/2021.04.16.440191; this version posted April 18, 2021. The copyright holder for this preprint (which

was not certified by peer review) is the author/funder, who has granted bioRxiv a license to display the preprint in perpetuity. It is made available under aCC-BY-ND 4.0 International license.

\section{DIETARY RESCUE OF FMR1 KNOCKOUT}

\section{Experimental Design}

The studies were broken up into two main experimental paradigms (Figure 1). In the first experimental paradigm, male offspring were maintained on standard laboratory chow until weaning on PD21. At PD21, animals were randomly assigned to one of three diet conditions: "Standard", "Omega-3" and "Control Fat". The latter two diets had identical lipid content $(50 \mathrm{~g} / \mathrm{kg})$. The Omega-3 condition received a diet enriched with fish oil and dyed with red food coloring to distinguish it from the control condition (Teklad Custom Diet TD.150384). To control for potential effects due to simply increasing fat content, the Control Fat diet contained olive and palm oils with no dyes (Teklad Custom Diet TD.1500385) (See Table 1 for Ingredients List). The dietary composition was based on levels previously used in this model (Pietropaolo et al., 2014). For further information of the types of fatty acid chains included, see Table 2. Mixed-genotype littermates were housed in groups no larger than 5 animals, with each cage receiving the same diet assignment. Based on the methodologies of prior studies, animals were maintained on this diet and tested in the behavioral paradigm started at PD90 (Pietropaolo et al., 2014). Animals were maintained on the diet throughout the testing paradigm. The behavior tests were ordered in a way that increased in invasiveness, to minimize the effect of training history on subsequent behavioral tests (Mcllwain, Merriweather, Yuva-Paylor, \& Paylor, 2001). The final sample sizes were as follows: standard diet WT $(n=11)$, standard diet KO $(n=10)$, control fat WT $(n=17)$, control fat KO $(n=15)$, omega-3 WT $(n=19)$, omega-3 KO $(n=16)$. Due to equipment errors, some data was not available for some animals for some behaviors, and final sample sizes for each behavioral test in this paradigm are delineated in Table 3.

In the second experimental paradigm, breeders were placed on one of the three experimental diets one week prior to pairing (Figure 1). Both parents and offspring were maintained on the assigned diet throughout pregnancy, parturition and lactation. Many aspects of the experimental diets were the same from paradigm 1, however, there were some additional nutrients added for breeding suitability (for a list of ingredients, see Table 4). Animals were then 


\section{DIETARY RESCUE OF FMR1 KNOCKOUT}

weaned onto standard laboratory chow on PD21 and housed with mixed genotype littermates in groups of no larger than 5 mice. Male animals were then tested in the behavioral battery beginning at PD60. The final sample sizes were as follows: standard diet WT $(n=24)$, standard diet KO $(n=12)$, control fat WT $(n=16)$, control fat KO $(n=16)$, omega-3 WT $(n=14)$, omega$3 \mathrm{KO}(\mathrm{n}=14)$. Due to equipment errors, some data was not available for all animals in some behaviors, and final sample sizes for each behavioral test for this paradigm are delineated in Table 5. Any additional data can be found in the Supplemental Material.

\section{Elevated Plus Maze}

The elevated plus maze task was performed to evaluate changes in baseline anxiety levels (Pellow, Chopin, File, \& Briley, 1985; Walf \& Frye, 2007). The testing room was lit by LED dimmable lamps (30 lux in the open arm) and the background noise remained at $60 \mathrm{~dB}$. The testing arena consisted of four arms $(30 \times 5 \mathrm{~cm})$ and a center platform $(5 \times 5 \mathrm{~cm})$ positioned approximately $40 \mathrm{~cm}$ above the floor. Two opposing arms were enclosed by acrylic walls. Animals were recorded for 10 minutes and their movement was assessed via Ethovision XT video tracking software (Noldus, Netherlands). This program scored the frequency and duration of visits to the various arms and center platform. The testing apparatus was cleaned thoroughly with $30 \%$ isopropyl alcohol solution before and after each subject was tested. Experimenters were not present during the testing window. Final sample sizes for each paradigm are delineated in Table 3 and Table 5.

\section{Sensorimotor Gating Assessment}

To determine changes in sensorimotor gating abilities in the Fmr1 KO mice, the sensorimotor gating assessment paradigm was implemented as previously described (Frankland et al., 2004). Briefly, the apparatus consisted of an acrylic hollow constraint tube, with varying degrees of restraint availability. This apparatus was mounted on a platform 


\section{DIETARY RESCUE OF FMR1 KNOCKOUT}

equipped to transduce startle response amplitude through the SR-Lab System (San Diego Instruments, San Diego, CA, USA). This paradigm consisted of three separate testing days. During all testing sessions, background levels were maintained at $68 \mathrm{~dB}$. On the first day, the animals underwent a habituation session. During this, they had a 5-minute acclimation session, followed by 80 startle stimuli delivered at a fixed interval $(15 \mathrm{~s})$. The startle stimulus was a 40 $\mathrm{ms}, 120 \mathrm{~dB}$ noise burst, with a rise/fall time of less than $1 \mathrm{~ms}$.

The next day, prepulse inhibition was assessed. Following a 5-minute habituation phase, animals received 20 presentations of a $40 \mathrm{~ms}, 120 \mathrm{~dB}$ stimulus. They were then presented with the prepulse phase of the trial, consisting of 90 trials. The first three trial types consisted of the $20 \mathrm{~ms}$ prepulse stimulus at three different decibel levels $(70,75$ and $80 \mathrm{~dB})$. The second three trial types then consisted of these three prepulse stimuli paired with the original startle stimulus. The prepulse stimulus was then preceded by the startle stimulus by $100 \mathrm{~ms}$. These trials were organized randomly and spaced by a $15 \mathrm{~s}$ inter-trial interval.

One week following the prepulse session, the startle threshold session was conducted. Following the initial 5-minute habituation period, mice were presented with 99 trials of 11 trial types: no stimulus, and ten startle stimuli ranging from $75-120 \mathrm{~dB}$ at five $\mathrm{dB}$ intervals. These startle stimuli lasted $40 \mathrm{~ms}$ with a rise/fall of less than $1 \mathrm{~ms}$. The order of these trials was pseudorandomized, such that 11 trials were presented as a block in a different order each time. Experimenters were not present during the testing window. Final sample sizes for both paradigms are delineated in Table 3 and Table 5.

\section{Delay Fear Conditioning}

The delay fear conditioning paradigm was conducted, as it has been shown to be selective for amygdala-based fear memories (Raybuck \& Lattal, 2011). On the first day of testing, following a 2 minute baseline period, the animals received 2 pairings of a 30 -second 80 $\mathrm{dB}$ white noise stimulus (designated the $\mathrm{CS}$ ) followed by a $0.7 \mathrm{~mA}$ shock stimulus (designated 


\section{DIETARY RESCUE OF FMR1 KNOCKOUT}

the US). Following each pairing, there was a 120 second inter-trial interval (ITI). The session lasted approximately 334 seconds.

On the second day, there were two testing sessions. During the first, the animal was placed in the familiar context and allowed to move freely for 300 seconds to evaluate freezing in the original context (contextual freezing behavior). Following a two-hour rest, the animal was placed in a new context for 360 seconds. The context was altered by the following manipulations: a clear acrylic square placed over the shock grid (novel tactile context), the shape of the arena altered by the insertion of an acrylic panel, shredded paper towels in the transfer cage and $1 \mathrm{~mL}$ of pure vanilla extract placed beneath the floor (novel olfactory context). During the first 3 minutes, we measured the freezing behavior of the mouse in a new environment. In the second 3 minutes, the CS was presented continuously for 3 minutes. During all sessions, freezing behavior was measured by an automated software (Colbourn Instruments, Allentown, PA, USA). Experimenters were not present during the testing window. Final sample sizes for this test for each experimental paradigm are delineated in Table 3 and Table 5.

\section{Quantitative Real-time Polymerase Chain Reaction for Cytokine Expression}

Soon after behavioral testing, the brain was removed and rinsed in $1 \mathrm{X}$ phosphate buffer (PBS) solution (for exact timing, please refer to Figure 1). Using previously described methods (Lugo et al., 2014), hippocampi were then rapidly dissected from each hemisphere and rapidly rinsed in ice cold $1 \mathrm{X}$ PBS, before being frozen on dry ice before stored in microcentrifuge tubes at $-80 \stackrel{\circ}{\mathrm{C}}$ until processing. The left hippocampus was used for all PCR assays. Total RNA was isolated from samples according to protocols from the RNeasy kit Qiagen, Hilden, Germany). Subsequently, concentration and purity of isolated samples were measured using a NanoDrop ND-1000 Spectrophotometer (Thermo Scientific, NanoDrop Products, Wilmington, DE). Using the High-Capacity cDNA Reverse Transcription Kit (Applied Biosystems, Carlsbad, CA), extracted RNA was then reverse transcribed into complementary DNA. Using a QuantStudio 5 


\section{DIETARY RESCUE OF FMR1 KNOCKOUT}

Real-Time PCR System (Applied Biosystems, Carlsbad, CA), mRNA expression was then determined by quantitative real-time polymerase chain reaction (qRT-PCR) using Taq-man probe and primer chemistry. Reactions were performed in triplicate in a 384 well plate for each sample, using the endogenous control gene ( $\beta$-actin) for normalization. The expression levels of each target gene, BDNF, IL-6, TNF- $\alpha$ and IL-1 $\beta$, was calculated by normalizing the quantified mRNA amount to $\beta$-actin using the 2- $\Delta \Delta C$ t method of quantitation. Relative gene expression of each group was calculated in relation to the Standard Diet WT group and used to test significance between groups.

\section{Statistical Analyses}

All data were analyzed using GraphPad Software 7.0 (San Diego, CA) or IBM SPSS Statistics 23 (Aramonk, NY). Results were evaluated using a $2 \times 3$ (Genotype [WT, KO] x Diet [Standard, Control Fat, Omega-3]) analysis of variance (ANOVA) on each dependent variable for the specific test. Any tests that involved repeated measures were analyzed using a withinsubjects factor, by repeated measures ANOVA (specified in the appropriate results section). Significant within-subjects interactions were followed up with individual one-way ANOVAs at each repeated measure. Significant interactions of genotype and diet were followed up with the use of a unique identifier for all groups (i.e. "Standard WT") and subsequent analysis. If there were multiple significant main effects, multiple comparisons were conducted using Fisher's LSD comparisons (Standard WT vs Standard KO, Standard WT vs Control Fat KO, Standard WT vs Omega-3 KO). For PCR, following a significant main effect, multiple comparisons were again conducted using Fisher's LSD comparisons. All results have been summarized for convenience in Tables 6 and 7. Correlations between cytokine expression levels and behavioral measures were conducted using Pearson's correlation statistic (results summarized in Table 8). For all inferential statistics, the level of significance remained at $p<0.05$. 


\section{DIETARY RESCUE OF FMR1 KNOCKOUT}

\section{RESULTS}

Prenatal but not post-weaning supplementation with a high omega-3 diet attenuated hyperactivity in the elevated plus maze in the Fmr1 knockout mouse.

Post-weaning Paradigm. Hyperactivity is a significant clinical component of FXS (Hagerman, 1997; Hagerman, Jackson, Levitas, Rimland, \& Braden, 1986), and has been welldescribed in the Fmr1 KO (Baker, Piven, \& Sato, 1998; Ding, Sethna, \& Wang, 2014; Nolan et al., 2017; Pietropaolo, Guilleminot, Martin, D'Amato, \& Crusio, 2011). Given the potential impact of hyperactivity on the findings of subsequent behavioral testing and the consistent appearance in the Fmr1 KO model, we assessed the impact of high omega-3 fatty acids on activity levels in the elevated plus maze. For the post-weaning paradigm, in the elevated plus maze, loss of Fmr1 did not influence distance moved, $F_{\text {genotype }}(1,76)=1.57, p=0.21$ (Figure 2A). Diet also did not influence distance moved, $F_{\text {diet }}(2,76)=0.32, p=0.74$. Moreover, there was no significant interaction of genotype and diet, $F_{\text {genotype } x \operatorname{diet}}(2,76)=2.75, p=0.07$.

A similar pattern was detected for velocity. Alone, loss of Fmr1 did not significantly increase velocity, $F_{\text {genotype }}(1,76)=0.88, p=0.35$ (Figure $2 \mathrm{~B}$ ) and diet did not significantly influence velocity on its own, $F_{\text {diet }}(2,76)=0.99, p=0.38$. Moreover, there was no interaction between genotype and diet, $F_{\text {genotype } \operatorname{diet}}(2,76)=2.96, p=0.06$.

Prenatal Paradigm. For the prenatal paradigm, in the elevated plus maze, loss of Fmr1 resulted in hyperactivity when measuring distance moved, $F_{\text {genotype }}(1,84)=21.04, p=0.001$ (Figure 2C). However, diet did significantly influence distance moved, $F_{\text {diet }}(2,84)=4.26, p=$ 0.02. Post-hoc multiple comparisons with LSD indicated that animals, across genotypes, receiving omega-3 fatty acids had reduced distance moved and velocity when compared to both standard and control fat conditions, $p<0.05$ (Figure 2C). A significant interaction was detected for distance moved, $F_{\text {genotype } \mathrm{xdet}}(2,84)=3.35, p=0.04$, and a follow-up analysis with unique group identifiers (i.e. Standard Diet WT) was conducted according to our a priori hypotheses. 


\section{DIETARY RESCUE OF FMR1 KNOCKOUT}

Interestingly, the control fat diet significantly exacerbated hyperactivity in the KO (Control Fat KO vs Standard WT, $p=0.02$ ). However, the control fat diet reduced hyperactivity in the wildtypes (Control Fat WT vs Standard WT, $p=0.004$ ). This was similarly true for the omega-3 WT diet (Omega-3 WT vs Standard WT, $p=0.01$ ). Further, the omega-3 KO group expressed levels of activity similar to the standard WT group, $p=0.62$ (Figure 2C), suggesting this rescued the phenotype seen in the Standard KO.

The results for velocity were similar. Overall, loss of $F m r 1$ increased velocity, $F_{\text {genotype }}(1$, $84)=14.41, p=0.001$ (Figure 2D). While no interaction was detected, $F_{\text {genotype } x \text { diet }}(2,84)=1.21$, $p=0.30$, exposure to the different dietary manipulations did indeed affect velocity, $F_{\text {diet }}(2,84)=$ 7.52, $p=0.001$. Post-hoc LSD comparisons indicated that the Omega-3 Diet ("b") condition significantly lowered velocity, relative to both the Standard Diet ("a") $(p=0.29)$, as well as the Control Fat ("a") diet $(p=0.001)$, suggesting that this aspect of hyperactivity was also rescued.

Overall, similar to the post-weaning paradigm, exposure to omega-3 fatty acids, but not other types of fatty acids, attenuates hyperactivity in the adult Fmr1 KO measured via the elevated plus maze.

Post-weaning exposure to high fat diets reversed startle threshold, while neither paradigm reversed $P P I$ deficits.

Post-weaning Paradigm. To examine the potential therapeutic efficacy of omega-3 fatty acids, we examined this behavior in a three-day paradigm similar to previously published methodology (Frankland et al., 2004). For the post-weaning paradigm, results for habituation to the startle stimulus (data not shown) indicated no impact of loss of $F m r 1$ on the ability to habituate to the chamber, $F_{\text {genotype }}(1,81)=0.001, p=0.97$, and this did not vary across the testing window, $F_{\text {genotype } x \text { time }}(7,567)=0.76, p=0.62$. Diet also did not impact habituation, $F_{\text {diet }}(2$, $81)=0.72, p=0.49$, and this effect did not change over time, $F_{\text {diet } x \text { time }}(14,567)=0.89, p=0.57$. The interaction of the different levels of genotype and diet were not significant, both overall, 


\section{DIETARY RESCUE OF FMR1 KNOCKOUT}

$F_{\text {genotype } \mathrm{xdiet}}(2,81)=1.91, p=0.16$, or across time, $F_{\text {genotype } \mathrm{x} \operatorname{diet} \mathrm{x} \text { time }}(14,567)=0.52, p=0.92$.

Overall, this indicated that neither diet nor genotype had a significant impact on habituation to the startle stimulus.

As expected, loss of Fmr1 resulted in overall exaggerated levels of prepulse inhibition (measured on Day 2), $F_{\text {genotype }}(1,81)=6.15, p=0.02$ (Figure 3A). This effect was consistent across decibel levels, $F_{\text {genotype } \mathrm{x} \text { decibel }}(2,162)=2.57, p=0.08$. Because this effect was consistent across the testing window, data is shown in the figure summarized across decibel level. Diet did not significantly impact percent inhibition alone, $F_{\text {diet }}(2,81)=0.05, p=0.95$, or across the levels of decibel of prepulse stimulus, $F_{\text {diet } x \text { decibel }}(4,162)=0.15, p=0.97$. Similarly, the combination of genotype and diet was not statistically significant depending on the levels of the stimulus, $F_{\text {genotype } x \text { diet } x \text { decibel }}(4,162)=0.15, p=0.96$. However, overall, the combination of these two factors differentially impacted percent inhibition, $F_{\text {genotype } \mathrm{x} \text { diet }}(2,81)=3.70, p=0.03$. Post-hoc analyses using LSD testing indicated that in standard diet condition, loss of Fmr1 exaggerated PPI [(a) Standard WT vs (b) Standard KO, $p=0.002]$. However, exposure to both the omega-3 [(a) Standard WT vs (b) Omega-3 KO, $p=0.04]$ and the control fat diet [(a) Standard WT vs (b) Control Fat KO, $p=0.05$ ] did not differentially impact the Fmr1 KO PPI phenotype (Figure 3A). Altogether, these results support previous findings that loss of Fmr1 results in exaggerated prepulse inhibition, though this was unaffected by the two post-weaning dietary manipulations.

Finally, startle threshold was assessed one week later. As expected, loss of Fmr1 did not impact the startle response overall, $F_{\text {genotype }}(1,81)=1.72, p=0.19$ (Figure 3B). However, there was a significant interaction of genotype and decibel levels, $F_{\text {genotype } x \text { decibel }}(10,810)=2.88$, $p=0.002$. Further investigation indicated that $F m r 1 \mathrm{KOs}$ had reduced startle responding during this testing window at higher stimulus levels (115 and $120 \mathrm{~dB}$ ). Diet exposure did not impact startle responding overall, $F_{\text {diet }}(2,81)=0.42, p=0.66$, and the slope of the startle threshold curve was not shifted, $F_{\text {diet } x \text { decibel }}(20,810)=0.98, p=0.38$. The overall combination of genotype and diet also failed to reach significance, $F_{\text {genotype } x \text { diet }}(2,81)=0.65, p=0.53$. However, these 


\section{DIETARY RESCUE OF FMR1 KNOCKOUT}

interaction of these levels of diet and genotype did significantly impact startle responding, $F_{\text {genotype } x \text { diet } x \text { decibel }}(20,810)=1.87, p=0.01$. Post-hoc analyses indicated that at $115 \mathrm{~dB}$ and 120 $\mathrm{dB}$, Standard KO demonstrated significantly reduced startle responding compared to Standard $\mathrm{WT}, p=0.05$. This was ameliorated by post-weaning exposure to both experimental diets at both $115 \mathrm{~dB}$ (Control Fat KO vs Standard WT, $p=0.97$; Omega-3 KO vs Standard WT, $p=$ 0.43 ) and $120 \mathrm{~dB}$ (Control Fat KO vs Standard WT, $p=0.94$; Omega-3 KO vs Standard WT, $p=$ 0.37) (Figure 3B). Together, these results suggest that increasing the fat content of the postweaning diet can potentially improve reduced startle responding at higher decibels in the Fmr1 KO.

Prenatal Paradigm. For the prenatal paradigm, loss of Fmr1 reduced responding to the startle stimulus overall, $F_{\text {genotype }}(1,84)=5.73, p=0.02$, during the habituation session (data not shown for this phase) and this effect become more significant over the testing window, $F_{\text {genotype } \mathrm{x}}$ time $(7,588)=2.01, p=0.05$. Moreover, diet did significantly impact overall responding to the startle stimulus, $F_{\text {diet }}(2,84)=3.49, p=0.04$. Further post-hoc LSD testing indicated that the omega-3 fatty acid diet increased startle responding, compared to the standard diet, at the level of $p<0.05$, regardless of genotype. This effect was consistent across time, $F_{\text {diet } x \text { time }}(14,588)=$ $1.59, p=0.08$. The control fat diet was not significantly different from either the standard or omega-3 diet. The unique combination of genotype and diet did not significantly impact startle responding during the habituation task, both overall, $F_{\text {genotype } \mathrm{xdiet}}(2,84)=0.35, p=0.70$, or across time, $F_{\text {genotype } \mathrm{x} \text { diet } \mathrm{xtime}}(14,588)=0.54, p=0.91$.

When looking at the prepulse inhibition phase, loss of Fmr1 significantly increased percent inhibition overall, $F_{\text {genotype }}(1,84)=7.74, p=0.01$ (Figure $3 C$ ). This sensitivity was also greater with increasing decibel levels, $F_{\text {genotype } x \text { decibel }}(2,168)=5.32, p=0.01$. Results also indicated that diet significantly altered percent inhibition, regardless of genotype, $F_{\text {diet }}(2,84)=$ 5.55, $p=0.01$. Post-hoc analyses indicated that the control fat diet significant increased PPI 


\section{DIETARY RESCUE OF FMR1 KNOCKOUT}

compared to the standard diet and omega-3 diet, while the omega-3 diet was not significantly different from the standard diet, at the level of $p<0.05$ (Figure 3C). This effect was not dependent on decibel levels, $F_{\text {diet } x \text { decibel }}(4,168)=1.93, p=0.11$. The combination of genotype and diet did not impact this behavior, both overall, $F_{\text {genotype } \operatorname{diet}}(2,84)=2.89, p=0.06$, and across decibel levels, $F_{\text {genotype } \mathrm{x} \text { diet } \mathrm{x} \text { decibel }}(4,168)=1.89, p=0.11$.

For the startle threshold test, loss of Fmr1 reduced startle responding at higher decibel levels, $F_{\text {genotype x decibel }}(10,840)=2.14, p=0.02$ (Figure 3D). This was not indicative of overall lowered startle responding in this task, $F_{\text {genotype }}(1,84)=0.02, p=0.88$. Diet also affected the startle threshold curve, both overall, $F_{\text {diet }}(2,84)=4.01, p=0.02$, and across the different levels, $F_{\text {diet } x \text { decibel }}(20,840)=2.89, p=0.001$. Overall, the combination of diet and genotype did not impact startle responding, $F_{\text {genotype } x \operatorname{diet}}(2,84)=0.28, p=0.76$. However, it did alter the threshold of startle responding, $F_{\text {genotype } \mathrm{x} \text { diet } \mathrm{x} \text { decibel }}(20,8840)=2.78, p=0.0001$. Subsequent analyses indicated the interaction between genotype and diet was only significant at the level of 110 and 115 decibels. Further testing indicated in WT animals, the omega-3 diet increased startle responding, [Omega-3 WT vs Standard WT, $p<0.05$; Omega-3 WT vs Standard KO, $p<0.05$; Omega-3 KO vs Standard WT, $p<0.05]$ (Figure 3D). Moreover, prenatal control fat diet shifted both the WT and KO animals to an intermediate position that was not statistically different between either group. Together these findings suggest that neither experimental diet improved reduced startle responding following loss of Fmr1.

Neither post-weaning nor prenatal omega-3 fatty acids influenced anxiety in the elevated plus maze, while prenatal monounsaturated fatty acids exacerbated anxiety changes seen in the Fmr1 knockout

Post-weaning Paradigm. Previous studies conducted in this model have indicated that nonsocial anxiety is significantly reduced following loss of Fmr1 (Liu \& Smith, 2009). To examine the influence of these dietary paradigms on anxiety, we assessed animals in the elevated plus maze, and recorded the percentage of time spent in open arms of the maze. For 


\section{DIETARY RESCUE OF FMR1 KNOCKOUT}

the post-weaning paradigm, loss of $F m r 1$ did not impact anxiety in this task, $F_{\text {genotype }}(1,76)=$ $0.003, p=0.96$, and diet was also not a significant factor, $F_{\text {diet }}(2,76)=2.03, p=0.14$ (Figure $4 \mathrm{~A})$. These variables also did not significantly interact, $F_{\text {genotype } \mathrm{x} \text { diet }}(2,76)=1.54, p=0.22$. The results suggest that the reduced anxiety characteristic of the $F m r 1 \mathrm{KO}$ is not present when tested around PD90 in this model, unlike previous studies conducted at an earlier time points (Nolan et al., 2017). Furthermore, neither dietary fatty acid manipulation affected the anxiety phenotype of either WT or KO animals.

Prenatal Paradigm. For the prenatal paradigm, loss of Fmr1 resulted in decreased anxiety, $F_{\text {genotype }}(1,84)=7.91, p=0.01$, as suggested by increased percentage of time spent in the open arms (Figure 4B). Increased time spent in the open arm in the Fmr1 KO was significantly exaggerated by exposure to the control fat diet, $F_{\text {diet }}(2,84)=8.01, p=0.001$. Posthoc analyses indicated that the control fat diet ("b") significantly increased the proportion of time spent in the open arms compared to both standard ("a") and omega-3 diets ("a"), at the level of $p<0.05$. However, the standard diet and omega-3 conditions produced similar effects (Figure 4B). Genotype and diet also did not significantly interact, $F_{\text {genotype } x \operatorname{diet}}(2,84)=2.10, p=0.13$. These results suggest that the omega-3 fatty acid diet did not improve altered anxiety characteristic of the Fmr1 model. Moreover, the control fat diet, similar to a typical Western diet, further exacerbated this reduced anxiety phenotype.

Post-weaning supplementation with high fat diets impairs training, contextual and cued recall, while prenatal supplementation improved training in the delay fear conditioning task.

Post-Weaning Paradigm. In previous studies of the Fmr1 KO, the delay fear conditioning paradigm demonstrates impaired acquisition of a fear response and impairments in cued recall (Nolan et al., 2017). Thus, we chose this paradigm to assess the ability of our treatment to improve this cognitive dysfunction. For the post-weaning paradigm, results for acquisition indicated no effect of loss of Fmr1 on freezing overall during the acquisition of a fear memory, 


\section{DIETARY RESCUE OF FMR1 KNOCKOUT}

$F_{\text {genotype }}(1,80)=1.06, p=0.31($ Figure $5 \mathrm{~A})$. This effect was consistent across time, $F_{\text {genotype } x}$ time $(4,320)=1.05, p=0.38$. Assignment to either one of the two experimental diets did, however, reduce freezing behavior during acquisition, $F_{\text {diet }}(2,80)=11.38, p=0.0001$. Moreover, the magnitude of this effect was different across the testing window, $F_{\text {diet } x \text { time }}(8,320)=5.99, p=$ 0.0001. In fact, beginning at tone 1, both omega-3 and control fat diets, across genotypes, displayed reduced levels of freezing, compared to standard diet controls, at the level of $p<$ 0.05 , and the magnitude of the difference grew over time. However, this effect was also dependent on genotype, as the interaction term was significant, both overall, $F_{\text {genotype } x \text { diet }}(2,80)$ $=3.18, p=0.05$, and across time, $F_{\text {genotype } \mathrm{x} \text { diet } \mathrm{xtime}}(8,320)=2.15, p=0.03$. Subsequent analyses indicated that this interaction reached significance only at the first inter-trial interval, the second presentation of the tone, and the second inter-trial interval at the level of $p<0.05$. Analysis using a unique grouping variable indicated that at ITI 1, tone 2 and ITI 2, all other groups displayed diminished freezing compared to the Standard WT group, at the level of $p<$ 0.05 (Figure 5A). Altogether, these results suggest that post-weaning exposure to both experimental diets reduced short-term learning of the association between the tone (CS) and shock (US) in this paradigm.

The next day, conditioning to the context was measured via freezing across the 5 minute window. As expected, loss of $F m r 1$ did not impact freezing behavior overall, $F_{\text {genotype }}(1,80)=$ 1.22, $p=0.27$ (Figure 5B). This effect was consistent across the testing window, $F_{\text {genotype } x \text { time }}(4$, $320)=1.61, p=0.17$. Diet did significantly impact freezing behavior to the conditioned context, $F_{\text {diet }}(2,80)=11.07, p=0.0001$. Subsequent analyses with LSD post-hoc multiple comparisons indicated that animals exposed to both omega-3 ("b") and control fat diets ("b") displayed significantly reduced freezing behavior in the conditioned context compared to the standard diet ("a"), $p<0.05$ (Figure 5B). This effect was consistent across the testing window, $F_{\text {diet } x \text { time }}(8$, $320)=0.19, p=0.83$. The combination of genotype and diet did not significantly impact freezing behavior, both overall, $F_{\text {genotype x diet }}(2,80)=1.63, p=0.20$, and across time, $F_{\text {genotype } x \text { diet x time }}(8$, 


\section{DIETARY RESCUE OF FMR1 KNOCKOUT}

$320)=1.37, p=0.21$. These results suggest that post-weaning exposure to the high-fat experimental diets reduces contextual fear learning.

Following a two-hour rest, animals were placed in a novel context and the level of conditioning to the stimulus was measured via freezing to the tone expression. Loss of Fmr1 did not alter freezing behavior across the testing window, $F_{\text {genotype }}(1,80)=1.0, p=0.76$ (Figure $5 \mathrm{C}$ ). This effect was consistent across time, $F_{\text {genotype } x \text { time }}(1,80)=1.46, p=0.23$. However, diet significantly impacted freezing overall during this window, $F_{\text {diet }}(2,80)=9.88, p=0.0001$. Further multiple-comparisons with LSD indicated that exposure to both omega-3 ("b") and control fat diets ("b") significantly reduce freezing behavior overall compared to the standard diet condition ("a") (Figure 5C). This effect was consistent across the testing window, $F_{\text {diet x time }}(2,80)=1.46, p$ $=0.24$. Because the effect on freezing was the same across the testing window, only freezing in response to the cue is shown in the figure. The combination of genotype and diet did not significantly impact freezing behavior, both overall, $F_{\text {genotype } x \operatorname{diet}}(2,80)=0.39, p=0.68$, and across time, $F_{\text {genotype } \mathrm{x} \text { diet } \mathrm{xtime}}(2,80)=2.04, p=0.14$. These results suggest that post-weaning exposure to both experimental diets reduced cued recall of the fear memory.

Prenatal Paradigm. For the prenatal paradigm, the results showed a different pattern. During the acquisition phase, loss of Fmr1 resulted in no change overall to freezing levels across the testing window, $F_{\text {genotype }}(1,90)=3.40, p=0.07$ (Figure 5D). However, the interaction of genotype and time did significantly impact freezing behavior, $F_{\text {genotype }}$ time $(4,360)=6.27, p=$ 0.001 (Figure 5D). As expected, post-hoc multiple comparisons indicated that loss of Fmr1 resulted in diminished freezing starting at the second iteration of the tone, at the level of $p<$ 0.05. Diet significantly impacted freezing overall during this acquisition phase, $F_{\text {diet }}(2,90)=5.08$, $p=0.01$, as well as across time, $F_{\text {diet } x \text { time }}(8,360)=3.34, p=0.001$. Further multiple comparisons testing indicated that both omega-3 fatty acid ("b") and control fat ("b") diets significantly increased freezing behavior across the testing window, at the level of $p<0.05$, and 


\section{DIETARY RESCUE OF FMR1 KNOCKOUT}

the magnitude of this effect increased over time (Figure 5D). There was also a trending interaction of genotype and diet, $F_{\text {diet } x \text { genotype }}(2,90)=2.77, p=0.07$, though this failed to reach significance. No significant three-way interaction was detected, $F_{\text {genotype } \mathrm{x} \text { diet } \mathrm{x} \text { time }}(8,360)=1.65, p$ $=0.11$. Overall, these results suggested that prenatal exposure to both experimental diets improved acquisition of a fear response in the Fmr1 KO.

Results for contextual fear conditioning, averaged across the 5 minute testing window, indicated no overall effect of genotype, $F_{\text {genotype }}(1,90)=0.47, p=0.50$ (Figure $5 \mathrm{E}$ ). No overall effect of diet was detected, $F_{\text {diet }}(2,90)=0.87, p=0.42$. Moreover, the different diet manipulations did not interact with genotype, $F_{\text {genotype } x \operatorname{diet}}(2,90)=0.77, p=0.47$.

Results for examining memory for the conditioned tone indicated firstly that loss of Fmr1 resulted in decreased freezing behavior across the test window, $F_{\text {genotype }}(1,90)=10.30, p=$ 0.002 (Figure 5F). This reduced freezing was significantly greater in response to the tone, $F_{\text {genotype x time }}(1,90)=11.63, p=0.001$ (Figure 5F). This decrement in freezing behavior was not, however, impacted by dietary manipulations, both overall, $F_{\text {diet }}(2,90)=0.66, p=0.52$, or across time, $F_{\text {diet } x \text { time }}(2,90)=0.62, p=0.54$. There was no significant between-subjects interaction of genotype and diet, $F_{\text {genotype } \operatorname{diet}}(2,90)=0.60, p=0.52$. No significant three-way interaction was detected, $F_{\text {genotype } x \text { diet } x \text { time }}(2,90)=0.13, p=0.55$. Overall, this suggests that the improvement in acquisition following prenatal exposure to these diets did not translate to cued recall the following day.

Prenatal and post-weaning exposure to high fat diets differentially impacts hippocampal proinflammatory cytokine and BDNF expression

Post-weaning Paradigm. Among the potential mechanisms potentially in play here, omega-3 fatty acids are known to normalize expression of cytokine signaling markers (Kang \& Weylandt, 2008; Pietropaolo et al., 2014). Following the conclusion of behavioral testing, expression of various cytokines in whole hippocampal samples was assayed. For the postweaning paradigm, no effect of genotype or diet was detected on: $\operatorname{BDNF}\left[F_{\text {genotype }}(1,29)=0.04\right.$, 


\section{DIETARY RESCUE OF FMR1 KNOCKOUT}

$\left.p=0.84 ; F_{\text {diet }}(2,29)=0.39, p=0.68 ; F_{\text {diet } x \text { genotype }}(2,29)=1.07, p=0.36\right]($ Figure $6 \mathrm{~A})$ or IL-1 $\beta$

$\left[F_{\text {genotype }}(1,29)=0.95, p=0.34 ; F_{\text {diet }}(2,29)=1.54, p=0.23 ; F_{\text {diet } x \text { genotype }}(2,29)=0.14, p=0.87\right]$

(Figure 6B). However, similar to previously published studies in our lab, IL-6 $\left[F_{\text {genotype }}(1,29)=\right.$

4.57, $p=0.04]$ (Figure 6C) and TNF- $\alpha\left[F_{\text {genotype }}(1,29)=7.91, p=0.01\right]$ (Figure 6D) were

significantly reduced following loss of Fmr1 (Hodges, Nolan, Reynolds, \& Lugo, 2017). TNF-a

was not significantly impacted by post-weaning exposure to any of the experimental diets, either overall, $F_{\text {diet }}(2,29)=0.40, p=0.67$, or according to genotype, $F_{\text {diet } x \text { genotype }}(2,29)=0.67, p=$ 0.52. However, dietary exposure to high levels of omega-3 fatty acids further reduced IL-6 expression, $F_{\text {diet }}(2,29)=4.29, p=0.02$. Post-hoc LSD multiple comparisons supported this conclusion, showing that exposure to the omega-3 diet significantly reduced IL-6 expression relative to the standard diet condition, $p<0.01$. Moreover, this effect was consistent across genotypes, $F_{\text {diet } x \text { genotype }}(2,29)=0.46, p=0.63$.

Prenatal Paradigm. For the prenatal paradigm, a total of 36 samples ( $\mathrm{n}=6$ per group) were used to assess hippocampal expression of proinflammatory cytokines and BDNF. No effect of genotype was detected for $\operatorname{BDNF}, F_{\text {genotype }}(1,30)=0.007, p=0.93$ (Figure 6E). However, exposure to both high fat diets reduced hippocampal expression of BDNF, $F_{\text {diet }}(2,30)$ $=7.38, p=0.003$. Post-hoc LSD multiple comparisons indicated that both high fat diets reduced hippocampal BDNF expression [(a) Standard Diet vs (b) Omega-3, $p=0.004$; (a) Standard Diet vs (b) Control Fat, $p=0.001$ ] (Figure 6E). This effect was consistent across the levels of genotype, $F_{\text {diet } x \text { genotype }}(2,30)=0.33, p=0.72$. A similar pattern was detected for IL-1 1 . No effect of genotype was detected, $F_{\text {genotype }}(1,30)=0.42, p=0.52$ (Figure $6 \mathrm{~F}$ ). However, exposure to the two dietary manipulations reduced expression of IL-1 $\beta, F_{\text {diet }}(2,30)=8.03, p=0.002$. Post-hoc LSD multiple comparison supported this [(a) Standard Diet vs (b) Omega-3 Diet, $p=0.001$; (a) Standard Diet vs (b) Control Fat Diet, $p=0.002$ ] (Figure 6F). This effect was consistent across genotypes as well, $F_{\text {diet x genotype }}(2,29)=0.16, p=0.85$. Unlike the post-weaning paradigm, no 


\section{DIETARY RESCUE OF FMR1 KNOCKOUT}

effects were seen for either IL-6 $\left[F_{\text {genotype }}(1,30)=0.04, p=0.84 ; F_{\text {diet }}(2,30)=2.62, p=0.09\right.$

$\left.F_{\text {diet } x \text { genotype }}(2,29)=0.02, p=0.98\right]($ Figure $6 \mathrm{G})$ or TNF-a $\left[F_{\text {genotype }}(1,30)=0.38, p=0.54 ; F_{\text {diet }}(2\right.$,

$\left.30)=2.16, p=0.13 ; F_{\text {diet } x \text { genotype }}(2,29)=0.11, p=0.89\right]$ (Figure $\left.6 \mathrm{H}\right)$. Overall, these results

suggest that prenatal exposure to both dietary manipulations reduced hippocampal expression of BDNF and IL-1 $\beta$ regardless of expression of $F m r 1$.

Reductions in proinflammatory cytokine and BDNF signaling are associated with fear conditioning performance

Post-weaning Paradigm. Given the nature of the experimental design used, it is difficult to determine if these changes in cytokine expression level are related to the changes we saw in behavior. Thus, we next aimed to determine if these changes were statistically associated with the behavioral phenotypes shown in the current study. These results are summarized in Table

8.

Given the decrements in acquisition seen following post-weaning administration of omega-3 fatty acids, we were most interested in whether the expression of IL-6 was associated with freezing behavior during the fear conditioning task. As expected, reductions in IL-6 expression were significantly associated with reductions in freezing behavior to the second presentation of the tone during the acquisition phase, $r(35)=0.40, p=0.02$ (Figure 7A). Reductions in IL-6 expression were also significantly associated with freezing behavior during the contextual phase of the paradigm, $r(35)=0.43, p=0.01$ (Figure 7B). However, this same pattern did not hold up for cued learning the second day, $r(35)=0.12, p=0.49$ (Figure $7 \mathrm{C}$ ). No other cytokines measured were significantly correlated with these measures, suggesting this is specific to IL-6. These results are in line with the understanding that cued learning is considered amygdala-dependent, while contextual conditioning is hippocampal-dependent (Raybuck \& Lattal, 2011). It is unclear what brain areas are involved with the acquisition phase of this task and thus the relationship between hippocampal IL-6 and individual differences in freezing 


\section{DIETARY RESCUE OF FMR1 KNOCKOUT}

behavior during the learning phase may instead reflect baseline differences in this model, as demonstrated previously, especially given the timeline of tissue processing (Hodges et al., 2017).

Given the studies showing that cytokine signaling predicts hyperactivity, we also wanted to determine if these reductions in IL-6 or other individual differences in expression levels were significantly associated with our measures of activity levels in the elevated plus maze (Han et al., 2017). The only significant association was between hippocampal expression of TNFa and velocity during the task, $r(35)=-.40, p<0.05$

Prenatal Paradigm. Similar to the post-weaning paradigm, correlations were conducted to ascertain if changes in cytokine expressions were related to any changes in behavior (summarized in Table 8). Given the improvements in fear learning acquisition seen in the preweaning paradigm concurrent with reductions in BDNF and IL-1 $\beta$ expression, we also assessed if the expression of BDNF and IL-1 $\beta$ was similarly associated with freezing behavior. Indeed, results of the Pearson correlation indicated that there was a significant negative association between hippocampal BDNF expression and freezing to the second tone during the acquisition phase, $r(35)=-.34, p=0.05$ (Figure 7D). Similar results were demonstrated for IL-1 $\beta$ expression in the hippocampus, $r(35)=-.35, p=0.04$ (Figure 7E). However, these cytokine levels were not significantly related to any other time point during the fear conditioning protocol.

Similar to the post-weaning paradigm, we found it pertinent to examine whether these reductions in cytokine signaling in the hippocampus were related to changes in activity levels. However, results suggested that no cytokines measured were significantly related to either velocity or distance moved in the elevated plus maze.

\section{DISCUSSION}




\section{DIETARY RESCUE OF FMR1 KNOCKOUT}

Hyperactivity is a significant clinical component of the FXS phenotype (Baumgardner, Reiss, Freund, \& Abrams, 1995; Fryns, Jacobs, Kleczkowska, \& van den Berghe, 1984; Hatton et al., 2002; RJ, 1987). Previous clinical studies demonstrated that treatment with omega-3 during a similar window reduced hyperactivity in individuals with ASD (Amminger et al., 2007). The hyperactivity phenotype is a consistent facet of the Fmr1 phenotype (Baker et al., 2010; Ding et al., 2014; Pietropaolo et al., 2011) and previous animal studies have indicated that treatment with anti-inflammatory agents also reduced hyperactivity (Dansie et al., 2013). Based on these findings, we hypothesized that dietary supplementation would ameliorate hyperactivity. Indeed, the results of the current study demonstrated that prenatal exposure to omega-3 fatty acids attenuated hyperactivity shown in the standard diet $\mathrm{KO}$ animals, though this was specific to prenatal supplementation (summarized in Figure 8). This effect was specific to the type of fatty acid, as the control fat diet had no impact on activity. This effect was concurrent with reductions in hippocampal BDNF expression as assessed by RT-PCR. While BDNF is typically considered a beneficial neurotrophic factor that promotes neuronal survival, in the Fmr1-null brain, BDNF-TrkB signaling is upregulated and loss of BDNF improves hyperactivity and altered sensorimotor gating in the Fmr1 model (Louhivuori et al., 2011; Uutela et al., 2012). Altogether, the results of the present study find that prenatal supplementation with omega- 3 fatty acids is sufficient to attenuate hyperactivity in the Fmr1 knockout, which is accompanied by changes in BDNF expression in the hippocampus.

Alterations in sensorimotor gating behaviors like startle responding are a significant clinical component for children with FXS, and these changes are also seen in the Fmr1 knockout (Frankland et al., 2004; Hagerman, 1997; Hagerman et al., 1986). Previous studies supported the possibility that this treatment would be effective, showing in the ketamine model of schizophrenia, changes in prepulse inhibition phenotypes are amenable to omega-3 fatty acids (Zugno et al., 2014). Results from both the post-weaning and prenatal paradigm indicated that the exaggerated PPI shown in the KO mouse was not affected exposure to either 


\section{DIETARY RESCUE OF FMR1 KNOCKOUT}

experimental diet, while reduced startle threshold was indeed ameliorated by post-weaning exposure to both omega-3 and control fat diets (summarized in Figure 8). Previous work has demonstrated that startle responding and inhibition of the startle response with a prepulse stimulus rely on separate circuitry and mechanisms, suggesting they may be differentially amenable to such treatments (Azzopardi, Louttit, DeOliveira, Laviolette, \& Schmid, 2018; Ison, Taylor, Bowen, \& Schwarzkopf, 1997). More work is needed to determine the mechanism that omega-3 fatty acids acted through to reverse deficits in startle responding.

The current study finds that the timing of the intervention also mattered for the impact on fear learning and memory (summarized in Figure 8). Clinical data demonstrates mixed findings regarding the efficacy of omega-3 fatty acids on aspects of cognition functioning (Jackson, Deary, Reay, Scholey, \& Kennedy, 2011; Lee, Shahar, Chin, \& Yusoff, 2013; Mazereeuw, Lanctôt, Chau, Swardfager, \& Herrmann, 2012; van de Rest et al., 2008). Yet, given that in a previous study omega-3's attenuated deficits in hippocampal-dependent novel object recognition in the knockout, we expected that other aspects of nonspatial hippocampaldependent memory might be similarly improved by this treatment (Pietropaolo et al., 2014). Conversely, the present studies found that post-weaning exposure to the two experimental diets diminished freezing behavior during acquisition, thus inhibiting learning of the acquired response. The differential acquisition of fear conditioning presents difficulty in interpretation of the contextual conditioning and cued recall results, as when tested 24 hours later, post-weaning exposure to the experimental diets also reduced contextual fear conditioning and cued recall, regardless of genotype. The discrepancy between our findings and the impact on memory processes shown in the previous study may be due to the inclusion of the standard diet control group. In the present study, the control fat diet mirrors a typical Western diet, which has been demonstrated to have its own effects on behavior (Peleg-Raibstein, Luca, \& Wolfrum, 2012; Williams, Seki, Vuguin, \& Charron, 2014 \& Charron, 2014). Thus, the inclusion of the standard diet control renders direct comparisons between our study and the previous study difficult. 


\section{DIETARY RESCUE OF FMR1 KNOCKOUT}

However, the prenatal paradigm resulted in improved acquisition of a fear response for both diets. Previous results have indeed similarly shown that manipulation of fat content can induce large changes in developing an appropriate fear response (Owada et al., 2006; Peleg-Raibstein et al., 2012; Sasaki, de Vega, Sivanathan, St-Cyr, \& McGowan, 2014; Sullivan, Riper, Lockard, \& Valleau, 2015). Overall, the present study adds to the knowledge that manipulation of fat content across the lifespan can significantly impact fear learning and memory.

A fundamental tenet of these experiments was that loss of Fmr1 would result in behavioral changes that mirror those previously seen. As hypothesized, we noted hyperactivity in the elevated plus maze, enhanced pre-pulse inhibition, a reduced startle threshold curve, and diminished fear learning. Moreover, no effect of loss of Fmr1 was noted on either social behavior or stereotypy (data found in Supplemental Material). These results are consistent with previous experiments conducted in our lab (Nolan et al., 2017) and others (Frankland et al., 2004). However, there were some unexpected findings, perhaps due to the shifts in behavioral time points across the two paradigms. For example, our results for the elevated plus maze indicated that loss of Fmr1 resulted in decreased anxiety only in the prenatal paradigm (around the age of PD60). However, when tested after PD90 (in the post-weaning paradigm), no effect of genotype was detected. The finding from the prenatal paradigm is congruent with our previous findings, demonstrating decreased anxiety around the same time point (Nolan et al., 2017). Similarly, no impairments in cued recall were detected in the post-weaning paradigm for the delay fear conditioning task, however we did see this effect in the prenatal paradigm. The timing again lines up with the previous study in conducted in our lab, and suggests that these impairments may not hold the same pattern after 3 months of age (Nolan et al., 2017). While the reason for this is unclear, this lack of effect at a later timepoint could reflect a shift to a different expression of the fear response. Many factors, including sex and individual differences, have been shown to result in divergent expression of fear responses (Bush, Sotres-Bayon, \& LeDoux, 2007; Gruene, Flick, Stefano, Shea, \& Shansky, 2015). Overall, much of the work in the Fmr1 


\section{DIETARY RESCUE OF FMR1 KNOCKOUT}

knockout adult phenotype has focused on the early ( PD60) adult phenotype, and the results of the present study clearly indicate a need to include more time points to fully elucidate the role of Fmr1 in fear learning.

A second fundamental hypothesis of this study was that changes in behavior resulting from these dietary manipulations could be related to changes in inflammatory cytokine signaling, and the results of this study broadly supported this. First, our results confirmed that reduction of hippocampal IL-1 $\beta$ is associated with improvements in acquisition of a fear response. Next, our results expanded on previous studies from our lab, showing that post-weaning treatment with omega-3 fatty acids reduced IL-6 expression levels (Hodges et al., 2017). Prior to conducting the study, we had anticipated that a normalization of hippocampal IL-6 expression would coincide with improvements in hippocampal dependent behaviors; however, the current study indicated that in conjunction with reduced IL-6 expression, post-weaning exposure to omega-3s was detrimental to hippocampal-dependent fear conditioning performance, but not our amygdala-dependent task. The IL-6 signaling molecule is important for many functions across the brain, including promotion of neuronal survival, protection against damage and modulation of neurotransmitter synthesis (Gadient \& Otten, 1997). In knockout studies, IL-6 has been demonstrated to be necessary for adequate performance in the novel object recognition task, as well as water maze performance, further suggesting its importance in normative hippocampal functioning (Baier, May, Scheller, Rose-John, \& Schiffelholz, 2009). Taken as a whole, these results support that constitutive expression of IL-6, rather than overall reduction, is important for proper hippocampal functioning in the Fmr1 model. This is in line with new evidence demonstrating that IL-6 may only take on a negative role in the presence of other proinflammatory cytokines (Raison, Knight, \& Pariante, 2018).

Altogether, the current study provides evidence of omega-3 fatty acids as a promising alternative to pharmaceuticals for individuals with FXS. Beyond coping with the burden of the disease itself, the importance of finding affordable treatment options cannot be overstated. 
bioRxiv preprint doi: https://doi.org/10.1101/2021.04.16.440191; this version posted April 18, 2021. The copyright holder for this preprint (which

was not certified by peer review) is the author/funder, who has granted bioRxiv a license to display the preprint in perpetuity. It is made

\section{DIETARY RESCUE OF FMR1 KNOCKOUT}

Nearly half of all families of children with FXS report a significant financial burden of the disease on their family, as out of pocket expenses can account for over $5 \%$ of family income (Ouyang, Grosse, Raspa, \& Bailey, 2010). Moreover, medication or therapy can account for over $50 \%$ of these out-of-pocket expenses (Ouyang et al., 2010). This financial burden can disproportionately affect low-income families, as low-income families with children with special health care needs are 11 times more likely than higher income families to have out-of-pocket medical expenditures exceeding 5\% of income (Newacheck \& Kim, 2005). Given the rising cost of pharmaceuticals (Lakdawalla, 2018), dietary interventions present as a more cost-effective alternative, further improving the lives of individuals with Fragile $\mathrm{X}$ syndrome.

\section{ACKNOWLEDGEMENTS}

The work in this study was supported by the National Institutes of [Grant NS088776] to JNL. We would like to acknowledge the use of equipment in the Molecular Biosciences Core.

\section{AUTHORSHIP CONTRIBUTIONS}

SN and JNL designed and organized the studies. SN, SH, MB, GS, JO, TJ, and BE collected and analyzed the data. SN wrote manuscript and $\mathrm{SH}, \mathrm{MB}, \mathrm{GS}, \mathrm{JO}, \mathrm{TJ}, \mathrm{BE}$, and JNL all provided critical review of the manuscript. JNL was responsible for fund acquisition. 


\section{DIETARY RESCUE OF FMR1 KNOCKOUT}

\section{REFERENCES}

Amminger, G. P., Berger, G. E., Schafer, M. R., Klier, C., Friedrich, M. H., \& Feucht, M. (2007). Omega-3 fatty acids supplementation in children with autism: a double-blind randomized, placebo-controlled pilot study. Biological Psychiatry, 61(4), 551-553. doi:10.1016/j.biopsych.2006.05.007

Ashwood, P., Krakowiak, P., Hertz-Picciotto, I., Hansen, R., Pessah, I., \& Van de Water, J. (2011). Elevated plasma cytokines in autism spectrum disorders provide evidence of immune dysfunction and are associated with impaired behavioral outcome. Brain, Behavior and Immunity, 25(1), 40-45. doi:10.1016/j.bbi.2010.08.003

Ashwood, P., Nguyen, D. V., Hessl, D., Hagerman, R. J., \& Tassone, F. (2010). Plasma cytokine profiles in Fragile $X$ subjects: Is there a role for cytokines in the pathogenesis? Brain, Behavior, And Immunity, 24(6), 898-902. doi:10.1016/j.bbi.2010.01.008

Azzopardi, E., Louttit, A. G., DeOliveira, C., Laviolette, S. R., \& Schmid, S. (2018). The role of cholinergic midbrain neurons in startle and prepulse inhibition. The Journal of Neuroscience, 38(41), 8798-8808. doi:10.1523/jneurosci.0984-18.2018

Baier, P. C., May, U., Scheller, J., Rose-John, S., \& Schiffelholz, T. (2009). Impaired hippocampus-dependent and -independent learning in IL-6 deficient mice. Behavioral Brain Research,, 200(1), 192-196. doi:10.1016/j.bbr.2009.01.013

Baker, Piven, J., \& Sato, Y. (1998). Autism and tuberous sclerosis complex: prevalence and clinical features. Journal of Autism and Developmental Disorders, 28(4), 279-285. doi:10.1023/A:1026004501631

Baker, K. B., Wray, S. P., Ritter, R., Mason, S., Lanthorn, T. H., \& Savelieva, K. V. (2010). Male and female Fmr1 knockout mice on C57 albino background exhibit spatial learning and memory impairments. Genes Brain Behav, 9(6), 562-574. doi:10.1111/j.1601183X.2010.00585.X

Baumgardner, T. L., Reiss, A. L., Freund, L. S., \& Abrams, M. T. (1995). Specification of the neurobehavioral phenotype in males with fragile X syndrome. Pediatrics, 95(5), 744-752.

Bongiovanni, K. D., Depeters, E. J., \& Van Eenennaam, A. L. (2007). Neonatal growth rate and development of mice raised on milk transgenically enriched with omega-3 fatty acids. Pediatric Research, 62(4), 412. doi:10.1203/PDR.0b013e31813cbeea

Bush, D. E. A., Sotres-Bayon, F., \& LeDoux, J. E. (2007). Individual differences in fear: Isolating fear reactivity and fear recovery phenotypes. Journal of Traumatic Stress, 20(4), 413422. doi:doi:10.1002/jts.20261

Cao, D., Kevala, K., Kim, J., Moon, H.-S., Jun, S. B., Lovinger, D., \& Kim, H.-Y. (2009). Docosahexaenoic acid promotes hippocampal neuronal development and synaptic function. Journal of Neurochemistry, 111(2), 510-521. doi:10.1111/j.14714159.2009.06335.x

Dansie, L. E., Phommahaxay, K., Okusanya, A. G., Uwadia, J., Huang, M., Rotschafer, S. E., . . . Ethell, I. M. (2013). Long-lasting effects of minocycline on behavior in young but not 


\section{DIETARY RESCUE OF FMR1 KNOCKOUT}

adult Fragile X mice. Neuroscience, 246(Supplement C), 186-198. doi:10.1016/j.neuroscience.2013.04.058

De Felice, C., Signorini, C., Durand, T., Ciccoli, L., Leoncini, S., D’Esposito, M., ... Hayek, J. (2012). Partial rescue of Rett syndrome by $\omega-3$ polyunsaturated fatty acids (PUFAs) oil. Genes \& Nutrition, 7(3), 447-458. doi:10.1007/s12263-012-0285-7

Ding, Q., Sethna, F., \& Wang, H. (2014). Behavioral analysis of male and female Fmr1 knockout mice on C57BL/6 background. Behavioral Brain Research, 271, 72-78.

doi:10.1016/j.bbr.2014.05.046

Eldho, N. V., Feller, S. E., Tristram-Nagle, S., Polozov, I. V., \& Gawrisch, K. (2003).

Polyunsaturated docosahexaenoic vs docosapentaenoic acid: Differences in lipid matrix properties from the loss of one double bond. Journal of the American Chemical Society, 125(21), 6409-6421. doi:10.1021/ja029029o

Fortunato, J. J., da Rosa, N., Martins Laurentino, A. O., Goulart, M., Michalak, C., Borges, L. P., ... Petronilho, F. (2017). Effects of omega-3 fatty acids on stereotypical behavior and social interactions in Wistar rats prenatally exposed to lipopolysaccarides. Nutrition, 35, 119-127. doi:10.1016/j.nut.2016.10.019

Frankland, P. W., Wang, Y., Rosner, B., Shimizu, T., Balleine, B. W., Dykens, E. M., .. . Silva, A. J. (2004). Sensorimotor gating abnormalities in young males with fragile $X$ syndrome and Fmr1-knockout mice. Molecular Psychiatry, 9(4), 417-425. doi:10.1038/sj.mp.4001432

Frankland, P. W., Wang, Y., Rosner, B., Shimizu, T., Balleine, B. W., Dykens, E. M., ... Silva, A. J. (2004). Sensorimotor gating abnormalities in young males with fragile $X$ syndrome and Fmr1-knockout mice. Mol Psychiatry, 9(4), 417-425. doi:10.1038/sj.mp.4001432

Frisardi, V., Panza, F., Seripa, D., Farooqui, T., \& Farooqui, A. A. (2011). Glycerophospholipids and glycerophospholipid-derived lipid mediators: a complex meshwork in Alzheimer's disease pathology. Progress in Lipid Research, 50(4), 313-330. doi:10.1016/j.plipres.2011.06.001

Fryns, J. P., Jacobs, J., Kleczkowska, A., \& van den Berghe, H. (1984). The psychological profile of the fragile X syndrome. Clinical Genetics, 25(2), 131-134.

Gadient, R. A., \& Otten, U. H. (1997). Interleukin-6 (IL-6)--a molecule with both beneficial and destructive potentials. Progress in Neurobiology, 52(5), 379-390.

Garay, P. A., Hsiao, E. Y., Patterson, P. H., \& McAllister, A. K. (2013). Maternal immune activation causes age- and region-specific changes in brain cytokines in offspring throughout development. Brain, Behavior, And Immunity, 31, 54-68. doi:10.1016/j.bbi.2012.07.008

Gruene, T. M., Flick, K., Stefano, A., Shea, S. D., \& Shansky, R. M. (2015). Sexually divergent expression of active and passive conditioned fear responses in rats. Elife, 4. doi:10.7554/eLife.11352 


\section{DIETARY RESCUE OF FMR1 KNOCKOUT}

Hagerman, \& Hagerman. (2002). Fragile X syndrome : diagnosis, treatment, and research (3rd ed.). Baltimore: Johns Hopkins University Press.

Hagerman, \& Sobesky. (1989). Psychopathology in fragile X syndrome. The American Journal Of Orthopsychiatry, 59(1), 142-152.

Hagerman, R. J. (1997). Fragile X syndrome. Molecular and clinical insights and treatment issues. West J Med, 166(2), 129-137. Retrieved from http://www.ncbi.nlm.nih.gov/pubmed/9109330

Hagerman, R. J., Jackson, A. W., 3rd, Levitas, A., Rimland, B., \& Braden, M. (1986). An analysis of autism in fifty males with the fragile X syndrome. Am J Med Genet, 23(1-2), 359-374.

Han, Y. M., Cheung, W. K., Wong, C. K., Sze, S. L., Cheng, T. W., Yeung, M. K., \& Chan, A. S. (2017). Distinct cytokine and chemokine profiles in autism spectrum disorders. Frontiers in Immunology, 8, 11. doi:10.3389/fimmu.2017.00011

Hatton, D. D., Hooper, S. R., Bailey, D. B., Skinner, M. L., Sullivan, K. M., \& Wheeler, A. (2002). Problem behavior in boys with fragile $\mathrm{X}$ syndrome. American Journal Of Medical Genetics, 108(2), 105-116.

Hodges, S. L., Nolan, S. O., Reynolds, C. D., \& Lugo, J. N. (2017). Spectral and temporal properties of calls reveal deficits in ultrasonic vocalizations of adult Fmr1 knockout mice. Behavioral Brain Research, 332, 50-58. doi:10.1016/j.bbr.2017.05.052

Hodges, S. L., Nolan, S. O., Taube, J. H., \& Lugo, J. N. (2017). Adult Fmr1 knockout mice present with deficiencies in hippocampal interleukin-6 and tumor necrosis factor-alpha expression. NeuroReport. doi:10.1097/wnr.0000000000000905

Ison, J. R., Taylor, M. K., Bowen, G. P., \& Schwarzkopf, S. B. (1997). Facilitation and inhibition of the acoustic startle reflex in the rat after a momentary increase in background noise level. Behavioral Neuroscience, 111(6), 1335-1352.

Jackson, P. A., Deary, M. E., Reay, J. L., Scholey, A. B., \& Kennedy, D. O. (2011). No effect of 12 weeks' supplementation with $1 \mathrm{~g}$ DHA-rich or EPA-rich fish oil on cognitive function or mood in healthy young adults aged 18-35 years. British Journal of Nutrition, 107(8), 1232-1243. doi:10.1017/S000711451100403X

Kang, J. X., \& Weylandt, K. H. (2008). Modulation of inflammatory cytokines by omega-3 fatty acids. Subcellular Biochemistry, 49, 133-143. doi:10.1007/978-1-4020-8831-5_5

Kaufmann, W. E., Cortell, R., Kau, A. S. M., Bukelis, I., Tierney, E., Gray, R. M., . . Stanard, P. (2004). Autism spectrum disorder in fragile $X$ syndrome: communication, social interaction, and specific behaviors. American Journal of Medical Genetics Part $A$, 129A(3), 225-234. doi:10.1002/ajmg.a.30229

Lakdawalla, D. N. (2018). Economics of the pharmaceutical industry. Journal of Economic Literature, 56(2), 397-449. 


\section{DIETARY RESCUE OF FMR1 KNOCKOUT}

Lee, L. K., Shahar, S., Chin, A. V., \& Yusoff, N. A. (2013). Docosahexaenoic acid-concentrated fish oil supplementation in subjects with mild cognitive impairment (MCI): a 12-month randomised, double-blind, placebo-controlled trial. Psychopharmacology (Berl), 225(3), 605-612. doi:10.1007/s00213-012-2848-0

Li, Q., Leung, Y. O., Zhou, I., Ho, L. C., Kong, W., Basil, P., . . McAlonan, G. M. (2015). Dietary supplementation with $\mathrm{n}-3$ fatty acids from weaning limits brain biochemistry and behavioural changes elicited by prenatal exposure to maternal inflammation in the mouse model. Transl Psychiatry, 5, e641. doi:10.1038/tp.2015.126

Liu, Z.-H., \& Smith, C. B. (2009). Dissociation of social and nonsocial anxiety in a mouse model of fragile X syndrome. Neuroscience Letters, 454(1), 62-66. doi:10.1016/j.neulet.2009.02.066

Louhivuori, V., Vicario, A., Uutela, M., Rantamaki, T., Louhivuori, L. M., Castren, E., ... . Castren, M. L. (2011). BDNF and TrkB in neuronal differentiation of Fmr1-knockout mouse. Neurobiology of Disease, 41(2), 469-480. doi:10.1016/j.nbd.2010.10.018

Lugo, J. N., Smith, G. D., Arbuckle, E. P., White, J., Holley, A. J., Floruta, C. M., . . Okonkwo, O. (2014). Deletion of PTEN produces autism-like behavioral deficits and alterations in synaptic proteins. Frontiers in Molecular Neuroscience, 7, 27. doi:10.3389/fnmol.2014.00027

Malkova, N. V., Yu, C. Z., Hsiao, E. Y., Moore, M. J., \& Patterson, P. H. (2012). Maternal immune activation yields offspring displaying mouse versions of the three core symptoms of autism. Brain, Behavior, And Immunity, 26(4), 607-616. doi:10.1016/j.bbi.2012.01.011

Mazereeuw, G., Lanctôt, K. L., Chau, S. A., Swardfager, W., \& Herrmann, N. (2012). Effects of omega-3 fatty acids on cognitive performance: a meta-analysis. Neurobiology of Aging, 33(7), 1482.e1417-1482.e1429. doi:10.1016/j.neurobiolaging.2011.12.014

Mcllwain, K. L., Merriweather, M. Y., Yuva-Paylor, L. A., \& Paylor, R. (2001). The use of behavioral test batteries: Effects of training history. Physiology \& Behavior, 73(5), 705717. doi:10.1016/S0031-9384(01)00528-5

Newacheck, P. W., \& Kim, S. E. (2005). A national profile of health care utilization and expenditures for children with special health care needs. Archives of Pediatrics \& Adolescent Medicine, 159(1), 10-17. doi:10.1001/archpedi.159.1.10

Nolan, S. O., Reynolds, C. D., Smith, G. D., Holley, A. J., Escobar, B., Chandler, M. A., . . Lugo, J. N. (2017). Deletion of Fmr1 results in sex-specific changes in behavior. Brain and Behavior, 7(10), e00800. doi:10.1002/brb3.800

Oh, D. Y., Talukdar, S., Bae, E. J., Imamura, T., Morinaga, H., Fan, W., . . Olefsky, J. M. (2010). GPR120 is an omega-3 fatty acid receptor mediating potent anti-inflammatory and insulin-sensitizing effects. Cell, 142(5), 687-698. doi:10.1016/j.cell.2010.07.041

Ouyang, L., Grosse, S., Raspa, M., \& Bailey, D. (2010). Employment impact and financial burden for families of children with fragile $X$ syndrome: findings from the National Fragile 


\section{DIETARY RESCUE OF FMR1 KNOCKOUT}

X Survey. Journal Of Intellectual Disability Research, 54(10), 918-928. doi:10.1111/j.1365-2788.2010.01320.x

Owada, Y., Abdelwahab, S. A., Kitanaka, N., Sakagami, H., Takano, H., Sugitani, Y., ... Kondo, $H$. (2006). Altered emotional behavioral responses in mice lacking brain-type fatty acidbinding protein gene. European Journal of Neuroscience, 24(1), 175-187. doi:doi:10.1111/j.1460-9568.2006.04855.x

Peleg-Raibstein, D., Luca, E., \& Wolfrum, C. (2012). Maternal high-fat diet in mice programs emotional behavior in adulthood. Behavioural Brain Research, 233(2), 398-404. doi:10.1016/j.bbr.2012.05.027

Pellow, S., Chopin, P., File, S. E., \& Briley, M. (1985). Validation of open : closed arm entries in an elevated plus-maze as a measure of anxiety in the rat. Journal of Neuroscience Methods, 14(3), 149-167. doi:10.1016/0165-0270(85)90031-7

Pietropaolo, S., Goubran, M. G., Joffre, C., Aubert, A., Lemaire-Mayo, V., Crusio, W. E., \& Laye, $S$. (2014). Dietary supplementation of omega-3 fatty acids rescues fragile $X$ phenotypes in Fmr1-Ko mice. Psychoneuroendocrinology, 49, 119-129. doi:10.1016/j.psyneuen.2014.07.002

Pietropaolo, S., Guilleminot, A., Martin, B., D'Amato, F. R., \& Crusio, W. E. (2011). Geneticbackground modulation of core and variable autistic-like symptoms in Fmr1 knock-out mice. PLOS ONE, 6(2), e17073. doi:10.1371/journal.pone.0017073

Raison, C. L., Knight, J. M., \& Pariante, C. (2018). Interleukin (IL)-6: A good kid hanging out with bad friends (and why sauna is good for health). Brain, Behavior, And Immunity, 73, 1-2. doi:10.1016/j.bbi.2018.06.008

Raybuck, J. D., \& Lattal, K. M. (2011). Double dissociation of amygdala and hippocampal contributions to trace and delay fear conditioning. PLOS ONE, 6(1), e15982. doi:10.1371/journal.pone.0015982

RJ, H. (1987). Fragile X syndrome. Current Problems in Pediatrics, 17(11), 626-674. doi:10.1016/0045-9380(87)90011-9

Sasaki, A., de Vega, W., Sivanathan, S., St-Cyr, S., \& McGowan, P. O. (2014). Maternal highfat diet alters anxiety behavior and glucocorticoid signaling in adolescent offspring. Neuroscience, 272, 92-101. doi:10.1016/j.neuroscience.2014.04.012

Sullivan, E. L., Riper, K. M., Lockard, R., \& Valleau, J. C. (2015). Maternal high-fat diet programming of the neuroendocrine system and behavior. Hormones and Behavior, 76, 153-161. doi:10.1016/j.yhbeh.2015.04.008

Turner, G., Webb, T., Wake, S., \& Robinson, H. (1996). Prevalence of fragile X syndrome. American Journal Of Medical Genetics, 64(1), 196-197. doi:10.1002/(sici)10968628(19960712)64:1<196::aid-ajmg35>3.0.co;2-g

Uutela, M., Lindholm, J., Louhivuori, V., Wei, H., Louhivuori, L. M., Pertovaara, A., . . Castrén, M. L. (2012). Reduction of BDNF expression in Fmr1 knockout mice worsens cognitive 


\section{DIETARY RESCUE OF FMR1 KNOCKOUT}

deficits but improves hyperactivity and sensorimotor deficits. Genes, Brain and Behavior, 11(5), 513-523. doi:doi:10.1111/j.1601-183X.2012.00784.x

van de Rest, O., Geleijnse, J. M., Kok, F. J., van Staveren, W. A., Dullemeijer, C., Olderikkert, M. G., ... de Groot, C. P. (2008). Effect of fish oil on cognitive performance in older subjects: a randomized, controlled trial. Neurology, 71(6), 430-438. doi:10.1212/01.wnl.0000324268.45138.86

Vancassel, S., Durand, G., Barthelemy, C., Lejeune, B., Martineau, J., Guilloteau, D., .. . Chalon, S. (2001). Plasma fatty acid levels in autistic children. Prostaglandins Leukot Essent Fatty Acids, 65(1), 1-7. doi:10.1054/plef.2001.0281

Veeraragavan, S., Bui, N., Perkins, J. R., Yuva-Paylor, L. A., Carpenter, R. L., \& Paylor, R. (2011). Modulation of behavioral phenotypes by a muscarinic M1 antagonist in a mouse model of fragile X syndrome. Psychopharmacology (Berl), 217(1), 143-151. doi:10.1007/s00213-011-2276-6

Walf, A. A., \& Frye, C. A. (2007). The use of the elevated plus maze as an assay of anxietyrelated behavior in rodents. Nature Protocols, 2(2), 322-328. doi:10.1038/nprot.2007.44

Williams, L., Seki, Y., Vuguin, P. M., \& Charron, M. J. (2014). Animal models of in utero exposure to a high fat diet: A review. Biochimica et Biophysica Acta, 1842(3), 507-519. doi:10.1016/j.bbadis.2013.07.006

Yehuda, S. (2012). Polyunsaturated fatty acids as putative cognitive enhancers. Medical Hypotheses, 79(4), 456-461. doi:10.1016/j.mehy.2012.06.021

Zugno, A. I., Chipindo, H. L., Volpato, A. M., Budni, J., Steckert, A. V., de Oliveira, M. B., .. . Gama, C. S. (2014). Omega-3 prevents behavior response and brain oxidative damage in the ketamine model of schizophrenia. Neuroscience, 259, 223-231. doi:10.1016/j.neuroscience.2013.11.049 


\section{DIETARY RESCUE OF FMR1 KNOCKOUT}

\section{Post-weaning Paradigm}

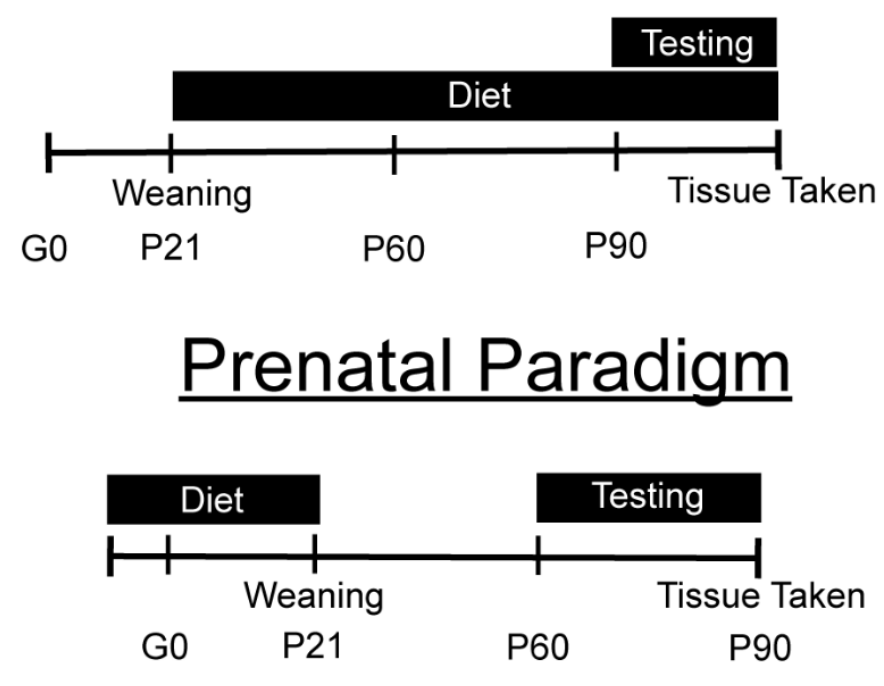

Figure 1. Overview of the two feeding paradigms. For the postnatal paradigm, the pups were weaned onto one of three dietary manipulations and maintained on this diet through the conclusion of the behavioral testing paradigm. For the prenatal paradigm, breeders were placed on the dietary manipulations for one week prior to pairing. Breeding pairs and litters were maintained on this diet until weaning on PD21, at which time male pups were weaned onto standard diet. All animals in this paradigm received standard diet from PD21 through the conclusion of testing. 


\section{DIETARY RESCUE OF FMR1 KNOCKOUT}

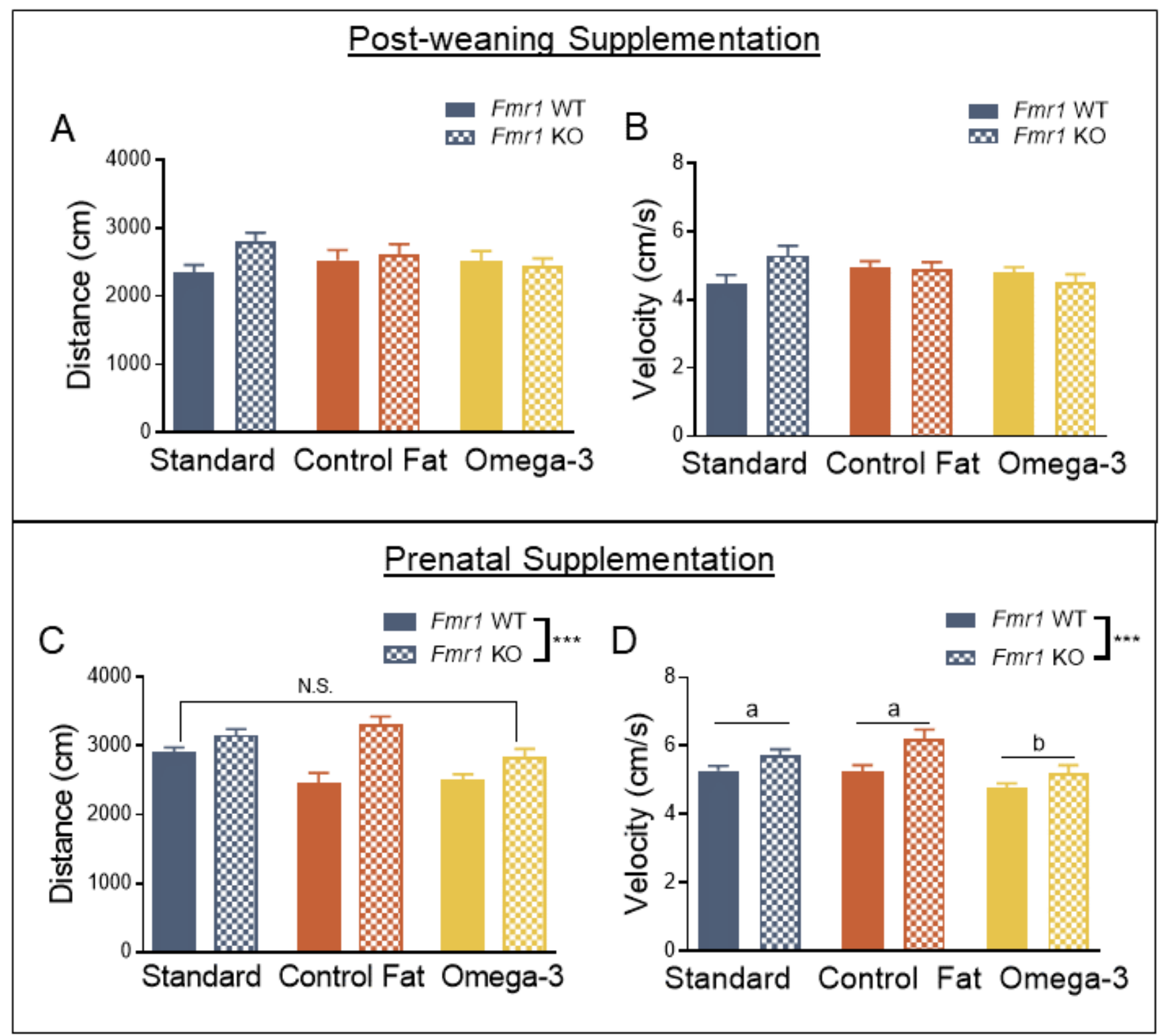

Figure 2. Prenatal supplementation with a high omega-3 diet attenuated hyperactivity in the elevated plus maze in the Fmr1 knockout mouse. A. Exposure to omega-3 fatty acids had no effect in the post-weaning paradigm as measured by distance moved in the elevated plus maze. B. A similar pattern was detected for velocity in the elevated plus maze. C. Prenatal exposure to omega-3 fatty acids reversed Fmr1 knockout induced hyperactivity in the elevated plus maze, as measured by distance moved. D. Prenatal exposure to omega-3s also reversed hyperactivity as measured by velocity in the elevated plus maze. Data are expressed as mean \pm SEM. ${ }^{* *}=\mathrm{P}<0.001$ ANOVA. A designation of "b" indicates that this group differed from the "a" comparison group at the level of $p<0.05$ in post-hoc analyses. 


\section{DIETARY RESCUE OF FMR1 KNOCKOUT}

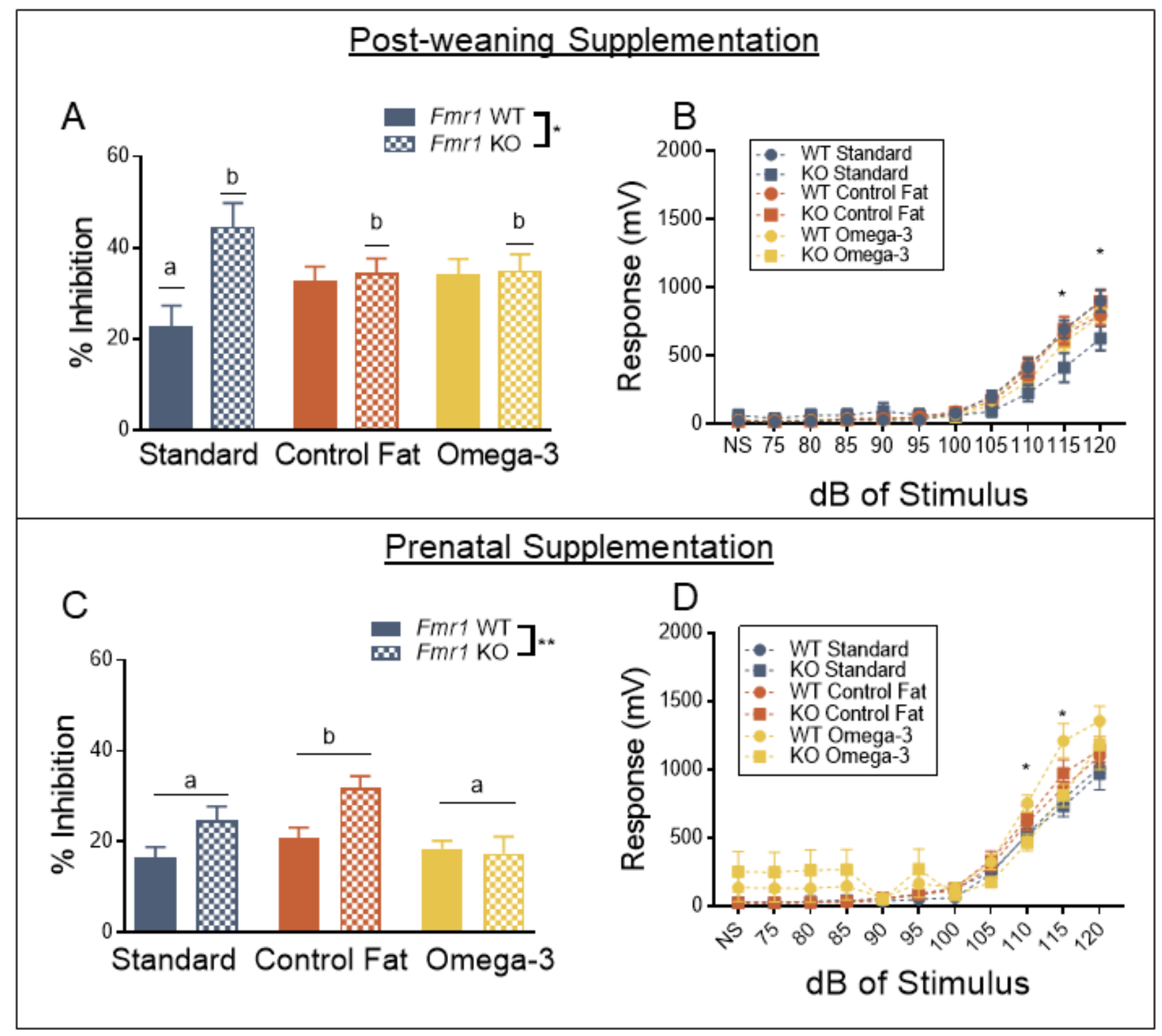

Figure 3. Post-weaning exposure to high fat diets reversed startle threshold, while neither paradigm impacted PPI deficits. A. Exposure to both experimental diets did not reverse exaggerated PPI in the Fmr1 knockout in the post-weaning paradigm. B. Startle threshold was diminished in the Fmr1 knockout, and this was reversed by exposure to the two experimental diets. C. Prenatal exposure to omega-3 fatty acids, nor the control fat diet, failed to reverse PPI deficits. D. Prenatal exposure to the experimental diets did not impact the startle threshold deficits seen in the Fmr1 knockout. Data are expressed as mean \pm SEM. ${ }^{*}=\mathrm{P}<0.05$ ANOVA, ${ }^{* *}=\mathrm{P}<0.01$ ANOVA. A designation of " $\mathrm{b}$ " indicates that this group differed from the "a" comparison group at the level of $p<0.05$ in post-hoc analyses. 


\section{DIETARY RESCUE OF FMR1 KNOCKOUT}

\section{Post-weaning Supplementation}

A

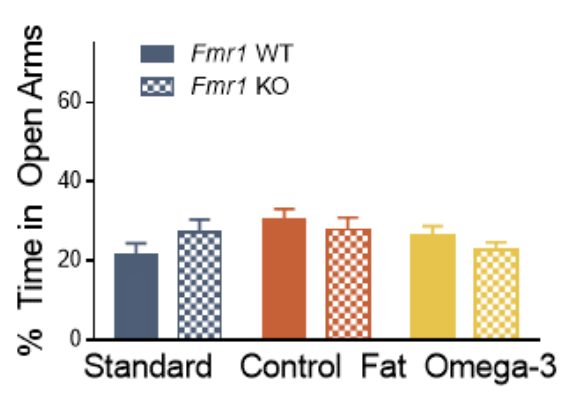

Prenatal Supplementation

B

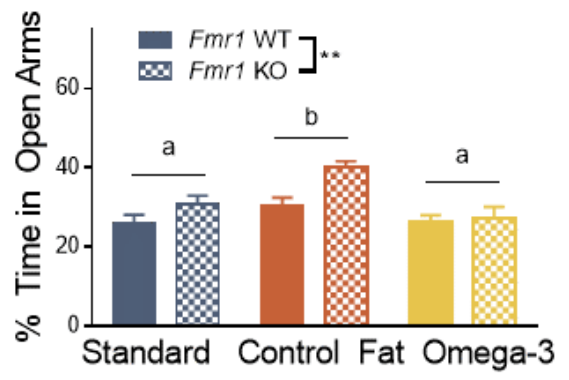

Figure 4. Neither post-weaning nor prenatal omega-3 fatty acids influenced anxiety in the elevated plus maze, while prenatal monounsaturated fatty acids exacerbated anxiety changes seen in the Fmr1 knockout. A. No effect of the experimental diets was seen in the post-weaning paradigm. B. Loss of Fmr1 was associated with diminished anxiety in the elevated plus maze, though this effect was not ameliorated by exposure to omega-3 fatty acids. Rather, exposure to the control fat diet exacerbated this genotype effect. Data are expressed as mean \pm SEM. ${ }^{* *}=\mathrm{P}<0.01$ ANOVA. A designation of "b" indicates that this group differed from the "a" comparison group at the level of $p<0.05$ in post-hoc analyses. 


\section{DIETARY RESCUE OF FMR1 KNOCKOUT}

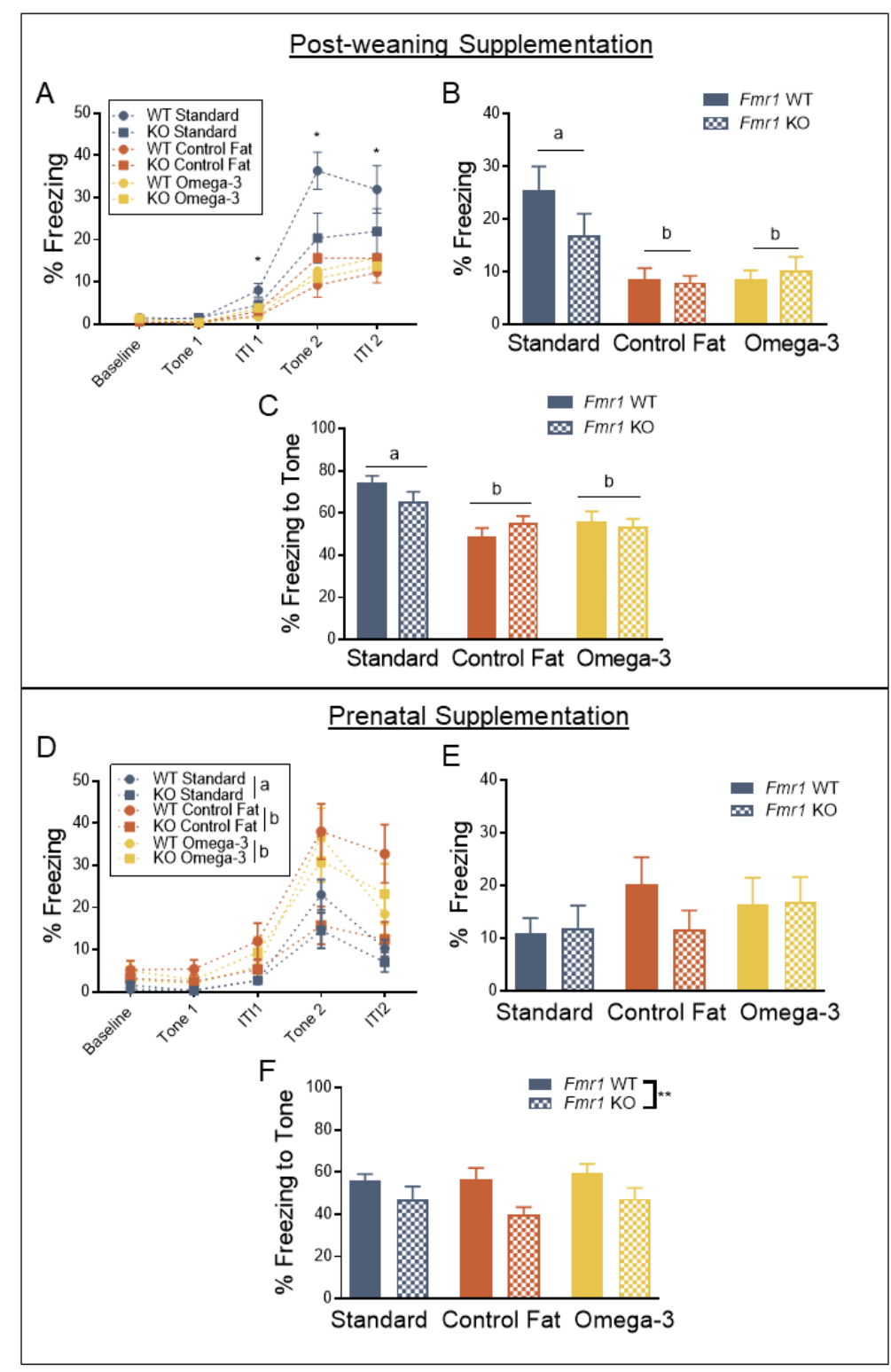

Figure 5. Post-weaning supplementation with high fat diets impaired training, contextual and cued recall, while prenatal supplementation improved training in the delay fear conditioning task. A. Acquisition of a fear memory was impaired by exposure to both experimental diets in wildtype animals, and this effect was not additive for the Fmr1 knockout. B. Contextual memory was impaired in both wildtype and knockout animals in the experimental diet conditions. C. Cued recall was impaired in wildtype and knockout animals, and this effect was not additive in the Fmr1 knockout. D. Prenatal omega-3 fatty acids improve training, while the control fat diet exhibits no effect. E. No effect of either diet or genotype was detected for contextual memory. F. No effect of either diet or genotype was detected for cued recall. Data are expressed as mean \pm SEM. ${ }^{*}=P<0.05$ ANOVA, ${ }^{* *}=P<0.01$ ANOVA. A designation of "b" indicates that this group differed from the "a" comparison group at the level of $p<0.05$ in post-hoc analyses. 


\section{DIETARY RESCUE OF FMR1 KNOCKOUT}

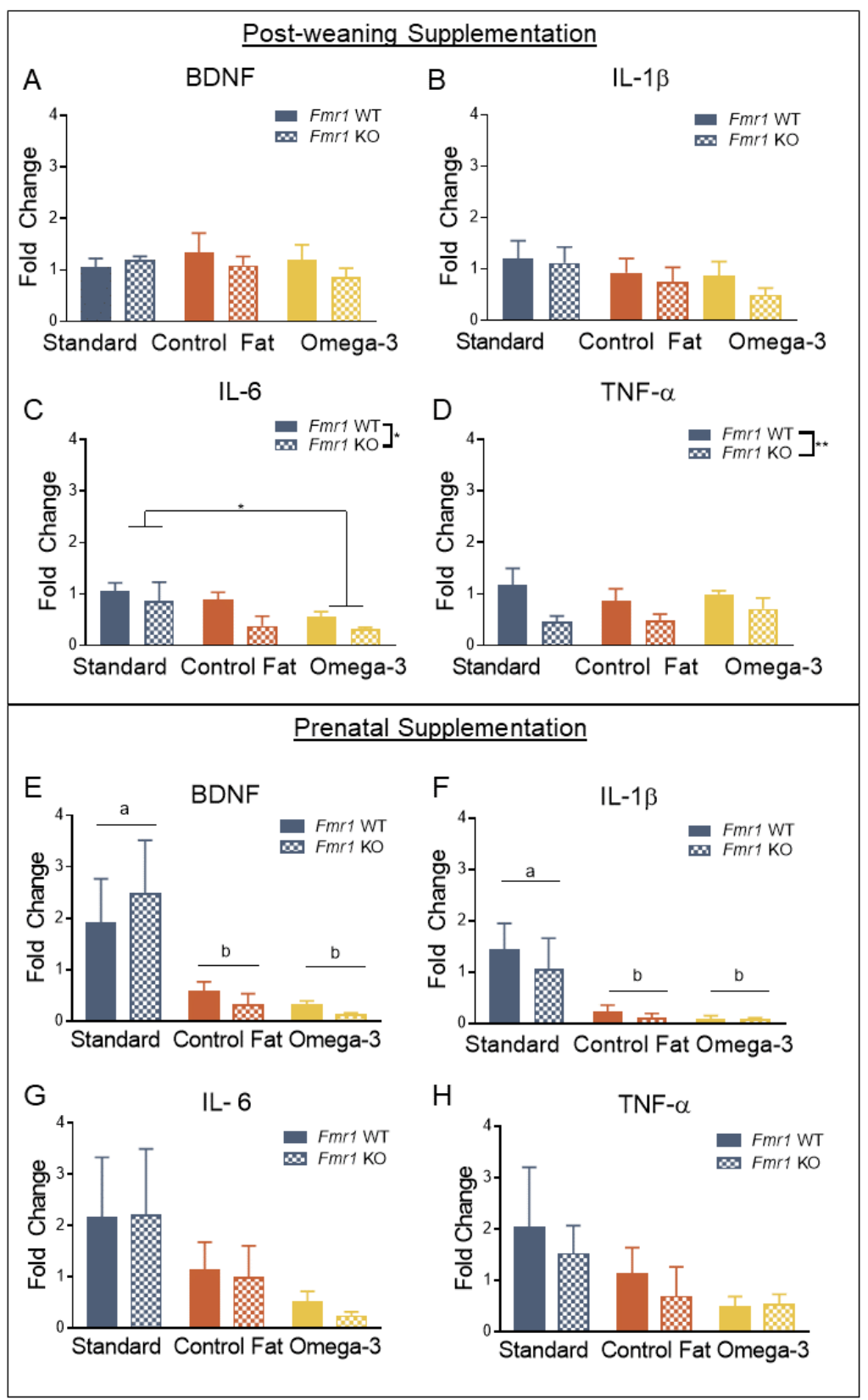

Figure 6. Prenatal and post-weaning exposure to high fat diets differentially impacted hippocampal proinflammatory cytokine and BDNF expression. A. Hippocampal expression of BDNF was not impacted by loss of Fmr1 or exposure to experimental diets. B. Hippocampal expression IL-1 $\beta$ was not impacted by loss of $F m r 1$ or exposure to experimental diets. C. Expression of IL-6 in the hippocampus was diminished in the Fmr1 knockout, and exposure to omega-3 fatty acids also reduced its expression. The control fat diet had no effect on IL-6 expression. D. TNF-a expression was also reduced in the Fmr1 knockout with no effect of diet. E. BDNF expression was reduced by both experimental diets. F. Similar to BDNF, IL-1 $\beta$ was reduced in the hippocampus of animals exposed to both experimental diets. G. Unlike the postnatal paradigm, no effect was detected for IL-6. H. No effects were detected for TNF-a. Data are expressed as mean \pm SEM. ${ }^{*}=\mathrm{P}<0.05$ ANOVA, ${ }^{* *}=\mathrm{P}<0.01$ ANOVA. A designation of "b" indicates that this group differed from the "a" comparison group at the level of $p<0.05$ in post-hoc analyses. 


\section{DIETARY RESCUE OF FMR1 KNOCKOUT}

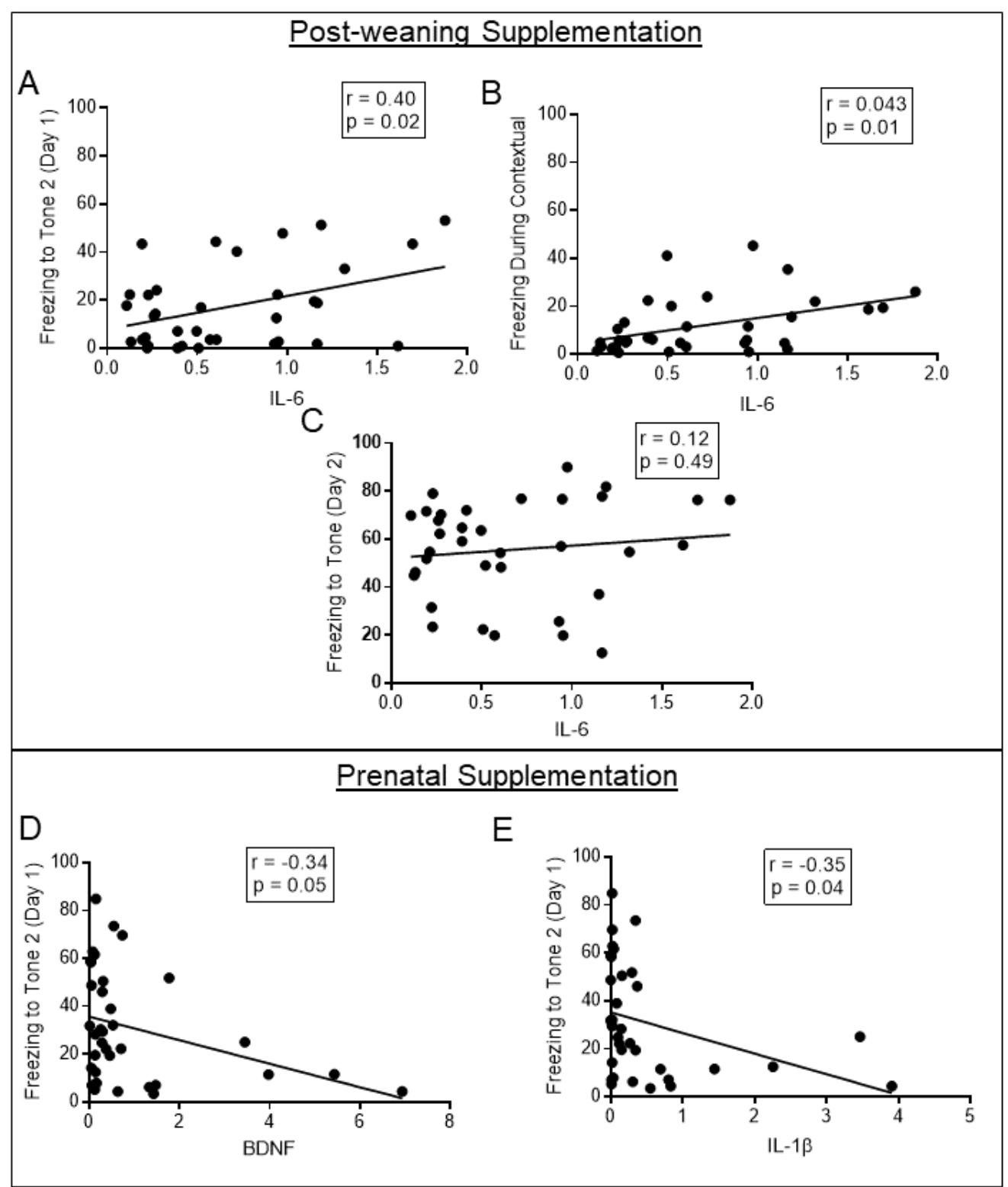

Figure 7. Reductions in proinflammatory cytokine and BDNF signaling were associated with fear conditioning performance. A. Reductions in hippocampal IL-6 expression were significantly associated with the reduced freezing behavior seen during the acquisition of delay fear conditioning, specifically during the second presentation of the tone. B. Similarly, reduced freezing behavior during the contextual phase was also significantly associated with IL-6 expression. C. The association between IL-6 and freezing during the cued recall phase was not significant. D. Concurrent with improvements seen in acquisition of a fear memory, BDNF is significantly negatively associated with freezing during the second presentation of the tone. $\mathrm{E}$. Similar results were found for IL-1 $\beta$ expression. Data points represents individual subject scores. 


\section{DIETARY RESCUE OF FMR1 KNOCKOUT}



Figure 8 Summary of the main findings. The results of the present study provide preliminary support for omega-3 fatty acids to ameliorate particular aspects of the Fmr $1 \mathrm{KO}$ phenotype, including hyperactivity and sensorimotor gating deficits. $\uparrow=$ increase in behavioral output; $\downarrow$ in behavioral output. For example, $\uparrow$ under $\mathrm{KO}$ activity level indicates hyperactivity. 


\section{DIETARY RESCUE OF FMR1 KNOCKOUT}

\begin{tabular}{ccc}
\hline Ingredients, g/kg & $\begin{array}{c}\text { Control for EPA and DHA } \\
\text { Diet } \\
\text { (Control Fat) }\end{array}$ & $\begin{array}{c}\text { Omega-3 EPA and } \\
\text { DHA Diet } \\
\text { (Omega-3 Diet) }\end{array}$ \\
\hline Casein & 200.0 & 200.0 \\
L-Cystine & 3.0 & 3.0 \\
Corn Starch & 347.472 & 347.472 \\
Maltodextrin & 132.0 & 132.0 \\
Sucrose & 100.0 & 100.0 \\
Canola Oil & 13.0 & 10.0 \\
Olive Oil & 65.0 & 20.0 \\
Palm Oil & 42.0 & 10.0 \\
Fish Oil & - & 80.0 \\
Cellulose & 50.0 & 50.0 \\
Mineral Mix, AIN- & 35.0 & 35.0 \\
93G & & 10.0 \\
Vitamin Mix, AIN- & 10.0 & \\
93 & & 2.5 \\
Choline Bitartrate & 2.5 & 0.028 \\
TBHQ, antioxidant & 0.028 & \\
\hline Total & 1000.0 & \\
\hline & &
\end{tabular}

Table 1. Diet Ingredients for Post-Weaning Paradigm. Ingredients for the experimental diets in the post-weaning supplementation paradigm (Teklad Custom Diet TD.1500384 and TD.1500385). 


\section{DIETARY RESCUE OF FMR1 KNOCKOUT}

\begin{tabular}{ccc}
\hline & Fatty Acids (\% of Total) & \\
& Control Fat Diet & Omega-3 Diet \\
SFA & 27.9 & 26.8 \\
MUFA & 59.8 & 36.8 \\
PUFA & 12.2 & 36.4 \\
$14: 00$ & 0.4 & 5.7 \\
$16: 00$ & 23.6 & 16.5 \\
$16: 01$ & 0.7 & 7.9 \\
$18: 00$ & 3.2 & 2.8 \\
$18: 01$ & 59.0 & 26.8 \\
$18: 02$ & 10.7 & 5.2 \\
$18: 03$ & 1.5 & 2.2 \\
$18: 04$ & 0.0 & 2.3 \\
$20: 5$ (EPA) & 0.0 & 10.7 \\
$22: 6($ DHA $)$ & 0.0 & 7.2 \\
n-3 & 1.5 & 22.6 \\
n-6 & 10.7 & 6.7 \\
\hline
\end{tabular}

Table 2. Fatty Acid Breakdown. Fatty acid breakdown for the experimental diets in the post-weaning supplementation paradigm (Teklad Custom Diet TD.1500384 and TD.1500385). 
bioRxiv preprint doi: https://doi.org/10.1101/2021.04.16.440191; this version posted April 18, 2021. The copyright holder for this preprint (which

was not certified by peer review) is the author/funder, who has granted bioRxiv a license to display the preprint in perpetuity. It is made available under aCC-BY-ND 4.0 International license.

\section{DIETARY RESCUE OF FMR1 KNOCKOUT}

\begin{tabular}{cccccccc}
\hline & \multicolumn{2}{c}{ Standard } & \multicolumn{2}{c}{ Control Fat } & \multicolumn{2}{c}{ Omega-3 } \\
Behavioral Test/Measure & WT & KO & WT & KO & WT & KO & Total \\
\hline Elevated Plus Maze & 9 & 10 & 14 & 16 & 17 & 16 & 82 \\
$\begin{array}{c}\text { Sensorimotor Gating } \\
\quad \text { Paradigms }\end{array}$ & 11 & 9 & 16 & 16 & 19 & 16 & 87 \\
Delay Fear Conditioning & 11 & 10 & 15 & 15 & 19 & 16 & 86 \\
qRT - PCR/Western Blots & 6 & 5 & 6 & 6 & 6 & 6 & 35 \\
\hline
\end{tabular}

Table 3. Sample Sizes for Post-Weaning Paradigm. Sample sizes for each behavioral test or measure following exclusion for technical or scoring issues. 


\section{DIETARY RESCUE OF FMR1 KNOCKOUT}

\begin{tabular}{|c|c|c|}
\hline Ingredients, g/kg & $\begin{array}{c}\text { Control for EPA and } \\
\text { DHA Diet } \\
\text { (Control Fat) }\end{array}$ & $\begin{array}{c}\text { Omega-3 EPA and DHA } \\
\text { Diet } \\
\text { (Omega-3 Diet) }\end{array}$ \\
\hline Casein & 200.0 & 200.0 \\
\hline L-Cystine & 3.0 & 3.0 \\
\hline Corn Starch & 341.60 & 341.60 \\
\hline Maltodextrin & 132.0 & 132.0 \\
\hline Sucrose & 100.0 & 100.0 \\
\hline Canola Oil & 13.0 & 10.0 \\
\hline Olive Oil & 65.0 & 20.0 \\
\hline Palm Oil & 42.0 & 10.0 \\
\hline Fish Oil & - & 80.0 \\
\hline Cellulose & 50.0 & 50.0 \\
\hline Mineral Mix AIN-93G & 35.0 & 35.0 \\
\hline Vitamin Mix AIN-93 & 10.0 & 10.0 \\
\hline Choline Bitartrate & 2.5 & 2.5 \\
\hline $\begin{array}{c}\text { Calcium Phosphate, } \\
\text { dibasic }\end{array}$ & 3.1 & 3.1 \\
\hline Calcium Carbonate & 1.0 & 1.0 \\
\hline Magnesium Oxide & 0.154 & 0.154 \\
\hline Cupric Carbonate & 0.0038 & 0.0038 \\
\hline Ferric Citrate & 0.2352 & 0.2352 \\
\hline $\begin{array}{c}\text { Sodium Selenite } \\
(0.0455 \% \text { in sucrose })\end{array}$ & 1.25 & 1.25 \\
\hline Vitamin $\mathrm{K}_{1}$, phylloquinone & 0.0003 & 0.0003 \\
\hline $\begin{array}{c}\text { Vitamin } \mathrm{B}_{12} \\
(0.1 \% \text { in mannitol })\end{array}$ & 0.025 & 0.025 \\
\hline TBHQ, antioxidant & 0.028 & 0.028 \\
\hline Total & 1000.0 & 1000.0 \\
\hline
\end{tabular}

Table 4. Diet Ingredients for Prenatal Paradigm. Ingredients for the experimental diets in the prenatal supplementation paradigm (TD.160486 and TD.160487). 


\section{DIETARY RESCUE OF FMR1 KNOCKOUT}

\begin{tabular}{cccccccc}
\hline & \multicolumn{2}{c}{ Standard } & \multicolumn{2}{c}{ Control Fat } & \multicolumn{2}{c}{ Omega-3 } \\
$\begin{array}{c}\text { Behavioral } \\
\text { Test/Measure }\end{array}$ & WT & KO & WT & KO & WT & KO & Total \\
\hline $\begin{array}{c}\text { Elevated Plus Maze } \\
\begin{array}{c}\text { Sensorimotor } \\
\text { Gating Paradigms }\end{array}\end{array}$ & 22 & 10 & 17 & 13 & 14 & 14 & 90 \\
$\begin{array}{c}\text { Delay Fear } \\
\text { Conditioning }\end{array}$ & 24 & 12 & 16 & 16 & 14 & 14 & 96 \\
qRT-PCR/Western & 6 & 6 & 6 & 6 & 6 & 6 & 36 \\
\hline Blots & & & 15 & 16 & 14 & 13 & 90 \\
\hline
\end{tabular}

Table 5. Sample Sizes for Prenatal Paradigm. Sample sizes for each behavioral test or measure following exclusion for technical or scoring issues. 


\begin{tabular}{|c|c|c|c|c|c|}
\hline & & & NOVA Results & & \\
\hline & & Genotype & Diet & Interaction & Post-Hoc Results \\
\hline & $\begin{array}{l}\text { Distance } \\
\text { Moved }\end{array}$ & $F(1,76)=1.57, p=0.21$ & $\begin{array}{c}\mathrm{F}(2,76)=0.32, \mathrm{p}= \\
0.74\end{array}$ & $\begin{array}{c}F(2,76)=2.75, p= \\
0.07\end{array}$ & \\
\hline $\begin{array}{l}\text { Elevated } \\
\text { Plus Maze }\end{array}$ & Velocity & $F(1,76)=0.88, p=0.35$ & $\begin{array}{c}F(2,76)=0.99, p= \\
0.38\end{array}$ & $\begin{array}{c}F(2,76)=2.96, p= \\
0.06\end{array}$ & \\
\hline & $\begin{array}{l}\% \text { Time in } \\
\text { Open Arms }\end{array}$ & $\begin{array}{c}\mathrm{F}(1,76)=0.003, \mathrm{p}= \\
0.96\end{array}$ & $\begin{array}{c}F(2,76)=2.03, p= \\
0.14\end{array}$ & $\begin{array}{c}F(2,76)=1.54, p= \\
0.22\end{array}$ & \\
\hline $\begin{array}{l}\text { Sensorimotor } \\
\text { Gating }\end{array}$ & $\%$ Inhibition & $F(1,81)=6.15, p=0.02$ & $\begin{array}{c}F(2,81)=0.05, p= \\
0.95\end{array}$ & $\begin{array}{c}F(2,81)=3.70, p= \\
0.03\end{array}$ & $\begin{array}{c}\text { Standard WT vs Standard } \\
\text { KO: } p=0.002 ; \text { Standard WT } \\
\text { vs Control Fat KO, } p=0.05 \\
\text { Standard WT vs Omega-3 } \\
\text { KO; } p=0.04\end{array}$ \\
\hline Assessment & $\begin{array}{c}\text { Startle } \\
\text { Responding }\end{array}$ & $\begin{array}{c}F(1,81)=1.72, p= \\
0.19^{\star}\end{array}$ & $\begin{array}{c}F(2,81)=0.42, p= \\
0.66\end{array}$ & $\begin{array}{c}F(2,81)=0.65, p= \\
0.53^{*}\end{array}$ & \\
\hline & Acquisition & $F(1,80)=1.06, p=0.31$ & $\begin{array}{l}F(2,80)=11.38, p \\
\quad=0.0001^{*}\end{array}$ & $\begin{array}{c}\mathrm{F}(2,80)=3.18, \mathrm{p}= \\
0.05^{\star}\end{array}$ & $\begin{array}{c}\text { At ITI 1, Tone } 2 \text { and ITI } 2- \\
\text { Standard WT vs All Groups, p } \\
<0.05\end{array}$ \\
\hline $\begin{array}{l}\text { Delay Fear } \\
\text { Conditioning }\end{array}$ & $\begin{array}{l}\text { Contextual } \\
\text { Fear } \\
\text { Conditioning }\end{array}$ & $F(1,80)=1.22, p=0.27$ & $\begin{array}{c}F(2,80)=11.07, p \\
=0.0001\end{array}$ & $\begin{array}{c}F(2,80)=1.37, p= \\
0.21\end{array}$ & $\begin{array}{c}\text { Standard vs Control Fat Diet, } \\
p<0.05 ; \text { Standard vs } \\
\text { Omega-3 Diet, } p<0.05\end{array}$ \\
\hline & Cued Recall & $F(1,80)=1.0, p=0.76$ & $\begin{array}{c}F(2,80)=9.88, p= \\
0.0001\end{array}$ & $\begin{array}{c}F(2,80)=0.39 p= \\
0.68\end{array}$ & $\begin{array}{c}\text { Standard vs Control Fat Diet, } \\
\mathrm{p}<0.05 ; \text { Standard vs } \\
\text { Omega- } 3 \text { Diet, } p<0.05\end{array}$ \\
\hline & BDNF & $F(1,29)=0.04, p=0.84$ & $\begin{array}{c}\mathrm{F}(2,29)=0.39, \mathrm{p}= \\
0.68\end{array}$ & $\begin{array}{c}\mathrm{F}(2,29)=1.07 \mathrm{p}= \\
0.36\end{array}$ & \\
\hline $\mathrm{P} \cap \mathrm{R}$ & $\mathrm{IL}-1 \beta$ & $F(1,29)=0.95, p=0.34$ & $\begin{array}{c}F(2,29)=1.54, p= \\
0.23\end{array}$ & $\begin{array}{c}F(2,29)=0.14, p= \\
0.87\end{array}$ & \\
\hline II & IL-6 & $F(1,29)=4.57, p=0.04$ & $\begin{array}{c}F(2,29)=4.29, p= \\
0.02\end{array}$ & $\begin{array}{c}F(2,29)=0.46, p= \\
0.63\end{array}$ & $\begin{array}{l}\text { Standard vs Omega-3 Diet, } \mathrm{p} \\
<0.05\end{array}$ \\
\hline & TNF- $a$ & $F(1,29)=7.91, p=0.01$ & $\begin{array}{c}\mathrm{F}(2,29)=0.40, \mathrm{p}= \\
0.67\end{array}$ & $\begin{array}{c}\mathrm{F}(2,29)=0.67, \mathrm{p}= \\
0.52\end{array}$ & \\
\hline
\end{tabular}

Table 6. ANOVA Results for Post-Weaning Paradigm. * = denotes significant interactions with within-subjects variable. See Results section for further information 


\begin{tabular}{|c|c|c|c|c|c|}
\hline & & Genotype & $\begin{array}{c}\text { ANOVA Results } \\
\text { Diet }\end{array}$ & Interaction & Post-Hoc Results \\
\hline \multirow{3}{*}{$\begin{array}{l}\text { Elevated Plus } \\
\text { Maze }\end{array}$} & Distance Moved & $\begin{array}{c}F(1,84)=21.04, p= \\
0.001\end{array}$ & $F(2,84)=4.26, p=0.02$ & $F(2,84)=3.35, p=0.04$ & $\begin{array}{c}\text { Control Fat KO vs Standard } \\
\text { WT, } p=0.02 ; \text { Control Fat WT } \\
\text { vs Standard WT, } p=0.004 \\
\text { Omega-3 WT vs Standard WT } \\
p=0.01 ; \text { Standard WT vs } \\
\text { Omega-3 KO, } p=0.62\end{array}$ \\
\hline & Velocity & $\begin{array}{c}\mathrm{F}(1,84)=14.41, \mathrm{p}= \\
0.001\end{array}$ & $\begin{array}{c}\mathrm{F}(2,84)=7.52, \mathrm{p}= \\
0.001\end{array}$ & $F(2,84)=1.21, p=0.30$ & $\begin{array}{c}\text { Standard vs Omega-3 Diet, } p \\
<0.05 ; \text { Control Fat vs Omega- } \\
\text { 3 Diet, } p<0.05\end{array}$ \\
\hline & $\begin{array}{c}\% \text { Time in Open } \\
\text { Arms }\end{array}$ & $F(1,84)=7.91, p=0.01$ & $\begin{array}{c}\mathrm{F}(2,84)=8.01, \mathrm{p}= \\
0.001\end{array}$ & $F(2,84)=2.10, p=0.13$ & $\begin{array}{l}\text { Standard vs Control Fat Diet, } \\
\qquad \mathrm{p}<0.05\end{array}$ \\
\hline \multirow{2}{*}{$\begin{array}{l}\text { Sensorimotor } \\
\text { Gating } \\
\text { Assessment }\end{array}$} & $\%$ Inhibition & $\begin{array}{c}\mathrm{F}(1,84)=7.74, \mathrm{p}= \\
0.01^{*}\end{array}$ & $F(2,84)=5.55, p=0.01$ & $F(2,84)=2.89, p=0.06$ & $\begin{array}{l}\text { Standard vs Control Fat Diet, } \\
\qquad \mathrm{p}<0.05\end{array}$ \\
\hline & $\begin{array}{c}\text { Startle } \\
\text { Responding }\end{array}$ & $\begin{array}{c}F(1,84)=0.02, p= \\
0.88^{\star}\end{array}$ & $\begin{array}{c}F(2,84)=4.01, p= \\
0.02^{*}\end{array}$ & $\begin{array}{c}F(2,84)=0.28, p= \\
0.76^{*}\end{array}$ & \\
\hline \multirow{3}{*}{$\begin{array}{l}\text { Delay Fear } \\
\text { Conditioning }\end{array}$} & Acquisition & $\begin{array}{c}F(1,90)=3.40, p= \\
0.07^{*}\end{array}$ & $\begin{array}{c}\mathrm{F}(2,90)=5.08, \mathrm{p}= \\
0.01^{*}\end{array}$ & $F(2,90)=2.77, p=0.07$ & $\begin{array}{c}\text { Standard vs Control Fat Diet, } \\
\mathrm{p}<0.05 ; \text { Standard vs Omega- } \\
\text { 3 Diet, } \mathrm{p}<0.05\end{array}$ \\
\hline & $\begin{array}{l}\text { Contextual Fear } \\
\text { Conditioning }\end{array}$ & $F(1,90)=0.47, p=0.50$ & $F(2,90)=0.87, p=0.42$ & $F(2,90)=0.77, p=0.47$ & \\
\hline & Cued Recall & $\begin{array}{c}F(1,90)=10.30, p= \\
0.002^{*}\end{array}$ & $F(2,90)=0.66, p=0.52$ & $F(2,90)=0.60, p=0.52$ & \\
\hline \multirow{4}{*}{ PCR } & BDNF & $\begin{array}{c}F(1,30)=0.007, p= \\
0.93\end{array}$ & $\begin{array}{c}F(2,30)=7.38, p= \\
0.003\end{array}$ & $F(2,30)=0.33, p=0.72$ & $\begin{array}{c}\text { Standard vs Omega-3 Diet, } p \\
=0.004 ; \text { Standard vs Control } \\
\text { Fat Diet, } p<0.0001\end{array}$ \\
\hline & IL-1 $\beta$ & $F(1,30)=0.42, p=0.52$ & $\begin{array}{c}\mathrm{F}(2,30)=8.03, \mathrm{p}= \\
0.002\end{array}$ & $F(2,30)=0.16, p=0.85$ & $\begin{array}{c}\text { Standard vs Omega- } 3 \text { Diet, } p \\
=0.001 ; \text { Standard vs Control } \\
\text { Fat Diet, } p=0.002\end{array}$ \\
\hline & IL-6 & $F(1,30)=0.04, p=0.84$ & $F(2,30)=2.62, p=0.09$ & $F(2,30)=0.02, p=0.98$ & \\
\hline & TNF- $a$ & $F(1,30)=0.38, p=0.54$ & $F(2,30)=2.16, p=0.13$ & $F(2,30)=0.11, p=0.89$ & \\
\hline
\end{tabular}

Table 7. ANOVA Results for Prenatal Paradigm. ${ }^{*}=$ denotes significant interactions with within-subjects variable. See Results section for further information 
Cytokine

\begin{tabular}{|c|c|c|c|c|c|c|c|c|c|c|}
\hline & 1 & 2 & 3 & 4 & 5 & 1 & 2 & 3 & 4 & 5 \\
\hline BDNF & -.13 & -.11 & .13 & -.06 & -.04 & $-.34^{\star}$ & -.25 & -.10 & .03 & -.07 \\
\hline IL-1 $\beta$ & .20 & .23 & .09 & .15 & .17 & $-.35^{\star}$ & -.27 & -.07 & .11 & .04 \\
\hline IL-6 & $.40^{\star}$ & $.43^{\star \star}$ & .12 & -.24 & -.22 & -.27 & -.09 & -.07 & .08 & .10 \\
\hline TNFa & .04 & .32 & .04 & -.33 & $-.40^{\star}$ & -.20 & -.17 & -.04 & -.008 & -.12 \\
\hline
\end{tabular}

Table 8. Cytokine Associations with Behavior for Both Paradigms. Variables Measured: 1) Acquisition Phase Response to Tone; 2) Freezing during Contextual Phase; 3) Freezing to Tone During Cued Recall Phase; 4) Distance Moved in EPM; 5) Velocity during EPM. ${ }^{*}=p<0.05 ;{ }^{* *}=p<0.01$. 